\title{
EIN UNBEKANNTES KAPITEL AUS MARX' LEBEN
}

\author{
BRIEFE AN DIE HOLLÄNDISCHEN VERWANDTEN
}

Während die Literatur über den Marxismus unübersehbar geworden ist, wurde der Erforschung von Marx' Persönlichkeit und Lebensgang nicht die erforderliche Aufmerksamkeit gewidmet, und zudem ist der grösste Teil der biographischen Literatur unkritisch. Das ist um so auffallender, als die Kenntnis der Marx-Biographie unerlässlich für das Verständnis des Marxismus ist; E. H. Carr hat darauf nachdrücklich hingewiesen. ${ }^{1}$ Es ist nun kein Geheimnis, dass Marx' Biographie grosse Lücken aufweist; über wichtige Ereignisse und ganze Abschnitte seines Lebens sind wir ungenügend unterrichtet. Selbst der Briefwechsel mit Engels, die Hauptquelle der Biographie, ist ein Torso; man darf annehmen, dass einige hundert Briefe fehlen. ${ }^{2}$ Nicht nur quantitativ ist das ein entsetzlicher Verlust; zweifellos sind sehr viele wichtige Briefe vernichtet worden. ${ }^{3}$ Engels selbst gab Marx einmal den Rat, bestimmte Briefe zu vernichten, was Marx jedoch bei der Gelegenheit nicht tat. ${ }^{4}$

Für die Kenntnis des Menschen Marx fehlen uns die wichtigsten Unterlagen. Wie war sein Verhältnis zur Familie, zur Mutter, zur Frau, zu Engels? Welche Motive und Einflüsse bestimmten die Wandlung seiner Beziehungen zu politischen Freunden und Gegnern? Rjazanov erinnert sich, Laura Lafargue einmal sein Bedauern darüber ausgesprochen zu haben, dass „Marx uns so wenig 'Subjektives', rein Persönliches hinterlassen" habe; sie habe ihm darauf die „Bekenntnisse" gezeigt ${ }^{5}$, mehr nicht. Gerade viel intimes Materıal ist verloren.

1 Karl Marx. London I938, S. VII.

2 Rjazanov in MEGA, Marx-Engels-Briefwechsel Bd. $3 \mathrm{~S}$. X f. Mehring in Grünbergs Archiv V, I9Is S. 4.

3 E. Bernstein an J.H.W. Dietz 31. Ш. '1 2: „Marx und Engels haben nun einmal mit vielen anderen ihrer Briefe auch ganz besonders interessante irgendwie verzettelt oder vernichtet." Nachlass.

4 Engels an Marx 16. VII 's8. Marx' und Engels' Briefe werden nach der MEGA, III. Abt. Bd. I-4 zitiert.

5 Die Neue Zeit 3 I. Jahrg. I9I3, I S. 854 ff. Siche auch Karl Marx als Denker, Mensch und Revolutionär, Wien-Berlin 1928, S. I 42 ff. Die „Bekenntnisse” s. S. 1027. 
So kann G. Mayer unter Berufung auf Bernstein und Rjazanov mitteilen, dass Laura und Eleanor Marx den ganzen Briefwechsel ihrer Eltern vernichteten, weil er Engels verletzende Stellen enthielt. ${ }^{1}$ Louise Freyberger spricht von wichtigen Marx-Briefen, die Engels sie habe lesen lassen, bevor er sie vernichtete. ${ }^{2}$ Durch die Beseitigung umfangreichen Materials wurde einmal der Legendenbildung ein weiter Spielraum geschaffen, zudem wurden viele Andeutungen in vorhandenen Briefen dunkel und verschiedener Interpretation fähig. Wie aus richtigen Zitaten durch oft unkundige Kommentierung bei feindseliger Voreingenommenheit eine schlechte Marx-Karikatur entstehen kann, zeigte kürzlich, ebenso einseitig wie die meisten Biographien, L. Schwarzschilds Darstellung. ${ }^{3}$

Bei der Vorbereitung der Veröffentlichung des Marx-Engels-Briefwechsels in den Jahren I910 bis I913 waren Veranstalter und Bearbeiter der Publikation mit Marx überhaupt in Verlegenheit. Der Marx des Briefwechsels ähnelte nicht dem Bilde, das man sich von ihm geschaffen hatte, und diesen Marx glaubte man weder Freund noch Gegner vorsetzen zu können. Eine umfangreiche Korrespondenz 4 gibt Auskunft über die Editionsprinzipien, d.h. vor allem die politischpropagandistischen und moralisierenden Begründungen der „Notwendigkeit" einer Verstümmelung der Briefe. Rjazanov hat später den Bearbeiter Bernstein in den Vorworten zu allen Briefbänden der MEGA auf das allerheftigste wegen dieser Verstümmelung angegriffen. Aber damals war die Verlegenheit allgemein, und Rjazanov selbst billigte gegenüber dem Verleger Dietz ausdrücklich die Arbeitsmethode Bernsteins: „Gestern war ich bei Bernstein, um die Arbeit anzusehen, weil ich keinen Begriff hatte, wieviel Briefe gedruckt werden und wie. Ich weiss nicht, ob Sie darauf bestanden hatten, aber in dieser Gestalt wird diese Arbeit keinen Anstoss finden bei den enragiertesten Antibernsteinianern. Es ist der beste Ausweg." 5 Irgend jemand regte gar an, die Korrespondenz zu verbrennen. ${ }^{6}$ Das MarxBild wurde seitdem durch viele neue Einzelzüge bereichert, nicht zuletzt durch die ungekürzte Veröffentlichung des Briefwechsels mit Engels. Er wurde von der Marx-Forschung bisher nicht ausgeschöpft, und auf weiten Strecken zeigt die biographische Darstellung die traditionellen Züge.

1 Friedrich Engels, Den Haag 1934, Bd. II, S. 356, 556.

2 Im Brief an A. Bebel vom 2. IX. '98, Abschrift im Bernstein-Nachlass. In diesem Zusammenhang führt sie auch Engels' Ausserung an: „Tussy wants to make an idol of her father."

3 Der rote Preusse. Stuttgart 1954.

- Etwa 180 Briefe von und an V. Adler, Bebel, Bernstein, Dietz, Kautsky, L. Lafargue, Mehring, Rjazanov, im IISG.

5 Brief Rjazanovs an Dietz ıo. IX. 'ro, in jener Sammlung.

- Erwähnt im Brief Dietz' an Bebel r.IV.'12, ebda. 
Diese Hinweise auf den Mangel an Quellen und die Lückenhaftigkeit der vorhandenen Quellen mögen genügen, um die Bedeutung alles neuen den Menschen Marx angehenden Materials zu kennzeichnen.

So wenig wie von Marx' Familienbeziehungen überhaupt, weiss man auch von seinen Beziehungen zu den holländischen Verwandten. „It is strange that my father's semi-Dutch parentage should be so little known", schrieb Eleanor Marx dem holländischen Sozialisten Henri Polak ${ }^{1}$, und sie gab ihm folgende Auskünfte über die holländischen Verwandten:

„...As to the question about my grandmother. Her family name was Presburg ${ }^{2}$, and she belonged by descent to an old Hungarian Jewish family. This family, driven by persecution to Holland, settled down in that country, and became known, as I have said by the name of Presburg - really the town from which they came. These Presburgs, of course, intermarried, and my grandmother's family name was afterwards Phillips. An uncle of my father was a fairly wealthy merchant, a very charming old man, I believe, whom my father very frequently visited at Amsterdam. This uncle had a large family, (my father's cousins) and there also father remained intimate with till about the time of the Commune. The uncle was then dead, and the cousins became too respectable and too frightened, and so I have now quite lost sight of them. One of these cousins is August Phillipps, a well-known advocate at Amsterdam; another Karl, was a cigar merchant, and lived I believe, at Aachen. But it was a very large family, and where they now all are I don't know. August (the advocate) at one time came to see us whenever his business brought him to London, and as I have said, my father was a frequent visitor at his uncle's house. To the day of her death my grandmother I believe (I did not know her, and was almost a baby when she died) spoke very bad German. But father, tho' of course he read and understood Dutch perfectly, did not speak it well..."

Einige dieser Angaben, so die von Eleanor Marx auch an anderer Stelle gebrachte Mitteilung über den ungarischen Ursprung der Familie, sind in den Biographien zu finden. Mehring vermutete auf Grund seiner Kenntnis der Marx-Engels-Korrespondenz, Marx

1 Brief vom 3r.X.'93, im Nachlass. Nachdem sie ihm am I9.X.'93 geschrieben hatte: "... Though my father was half Dutch, I only read Dutch a very little", erkundigte er sich vermutlich nach dieser halb holländischen Abstammung.

2 Als Presborck erscheint der Name in Marx' Geburtsurkunde 1818 , als Presburg in einer Kopie dieser Utkunde 1838 und im „Inventaris van de Nalatenschap” der Mutter, s.S. 61 . Pressburg ist die deutsche Schreibweise. 
scheine in späteren Jahren seinen mütterlichen Verwandten in Holland näher gestanden zu haben, „namentlich einem 'Onkel' Philips; er spricht von diesem 'famosen alten Jungen', der sich ihm auch in den Nöten des Lebens hilfreich erwies, wiederholt mit grosser Sympathie."1 Die „Chronik” 2, in der zum erstenmal alle biographischen Daten über Marx gesammelt wurden, bringt über die holländischen Verwandten vor allem die im Briefwechsel anzutreffenden Hinweise. So wenig wie Eleanors sind auch ihre Angaben ganz frei von Irrtümern. ${ }^{3}$ In der zeitgenössischen holländischen Literatur blieben diese Familienbeziehungen unberücksichtigt. ${ }^{4}$

Die bewahrt gebliebenen und hier zum Abdruck kommenden Briefe Marxscher Familienmitglieder an die holländischen Verwandten füllen den dürftigen Rahmen der uns bekannten Daten wenigstens etwas aus. Sie kamen durch einen glücklichen Umstand in den Besitz des I.I.S.G. und wurden hier in den Marx-Nachlass eingefügt. Es handelt sich um zwölf Briefe von Marx, davon sieben an Lion und fünf an Nannette Philips, zwei Briefe von Jenny Marx an Nannette Philips, zwei Briefchen von Eleanor Marx an Lion Philips, sechs Briefe der Mutter Henriette und der Schwestern Louise und Emilie Marx, - von diesen Schwestern waren bisher keine Briefe bekannt, an Lion und Sophie Philips und an Henriette van Anrooy-Philips und schliesslich um „Bekenntnisse” von Marx' Hand. Der Sammlung wurden ferner drei Briefe August Philips' an Marx aus dessen Nachlass beigefügt, vermutlich die einzigen Briefe, die von Philips' Seite an Marx erhalten sind. Die verwandtschaftlichen Beziehungen werden aus den Briefen deutlich, sie erfordern kaum Erläuterungen. Alle Cousins und Cousinen werden in den Briefen erwähnt. Henriette van Anrooy-Philips war nach Marx' Mutter genannt, wie seine älteste Schwester Sophie ihren Namen von der Tante Philips erhalten hatte. August Philips war Advokat in Amsterdam; die im Zusammenhang mit ihm genannte Lonne ist seine Gattin Madelon. Jacques Philips war Advokat in Rotterdam, Karl und Jean Philips betrieben ein Tabakgeschäft in Aachen, und Fritz übernahm das Bankhaus in

1 Karl Marx. Leipzig 1918, S. 4.

2 Karl Marx. Chronik seines Lebens. Moskau 1934.

3 Philips war später der Familienname der Schwester der Grossmutter. Der Onkel wohnte in Zaltbommel. Eleanor war neun Jahre alt, als dieGrossmutter starb. - In der MEGA wird III. Abt. Bd. 4 S. 698 u. ö. Jacques Philips als Onkel und Lion Philips als Vetter Marz' bezeichnet; ferner wird der Brief August Philips' an Engels aus dem Jahre 1847 Lion Philips zugeschrieben, s.S. 53. In der „Chronik” wird S. $4^{\circ} 9$ Nannette als Frau Dr. van Anrooys bezeichnet; das war aber ihre Schwester Henriette Philips.

4 S. A. Kerdijk, Karl Marx, Haarlem 1879, obwohl die Beziehungen bekannt waren; denn der Verleger setzte sich auf Wunsch des Verfassers mit Marx' Schwager Juta in Verbindung, um Marx zur Erteilung von biographischen Auskünften zu bewegen, die er dann auch gab. S. auch F. Domela Nieuwenhuis, Karl Marx in De Dageraad, Mai 1883. 
Zaltbommel. Nannette Philips endlich, zu der Marx' Freundschaft besonders herzlich war, zählte zu Beginn der Korrespondenz fünfundzwanzig Jahre, im Jahre $187 \mathrm{r}$ wurde sie die Gattin des auch in den Briefen genannten Pfarrers Roodhuizen und starb, erst achtundvierzig Jahre alt, im Jahre 188 s.

Zum erstenmal war Marx wahrscheinlich in den Weihnachtsferien I 835 als Student von Bonn aus in Nijmegen zu Besuch. ${ }^{1}$ Wir wissen nicht, wen er von der mütterlichen Familie dort antraf; der Grossvater Isaac Presburg war I 825 gestorben. ${ }^{2}$ Die Mutter erkundigt sich, wie dem Sohne ihre Vaterstadt gefallen habe; die Lage sei recht schön, und hoffentlich habe sie ihm Stoff zu einem Gedicht gegeben! Die nächste Spur finden wir Ende März 1843; Marx kam aus Köln, er hatte gerade die Redaktion der Rheinischen Zeitung niedergelegt. „Auf der Trekschuit nach D." ist der erste Brief an Ruge datiert, der die Deutsch-französischen Jahrbücher eröffnen sollte ${ }^{3}$; er enthält die Versicherung, man empfinde in Holland Scham über die deutschen Zustände, und der kleinste Holländer sei noch ein Staatsbürger gegen den grössten Deutschen. Sicherlich hat Marx auf dieser Reise die Verwandten der Mutter in Zaltbommel besucht, in deren Kreise er jene Erkenntnis durch die lebendige Anschauung gewann. Auch für die nächsten Jahre, die Zeit der Paris-Brüsseler Emigration, fehlt es sehr an persönlichen Zeugnissen; doch wissen wir, dass der Vetter August Philips Marx in Brüssel besuchte. Er fügte Marx' Brief an Engels vom 15. Mai I 847 eine Nachschrift bei, die von einem sehr freundschaftlichen Verhältnis zwischen dem Vetter und Engels zeugt:

Mein liebes Fritzchen,

Ich bin eben im Begriff, Deine Broschüre ${ }^{4}$ zu durchlesen - bis jetzt habe ich daran viel Spass gehabt - und fühle mich ganz glücklich, kein Deutscher nicht zu sein. Gott oder Vernunft oder Gattung bewahre uns vor der Kleinbürgerei!!

Avec laquelle j'ai l'honneur d'être

P.S. Schreibe mir doch mal un demi mot.

Yours most truly Philips.

Es ist nicht bekannt, wann August Philips Engels kennen lernte und

1 Brief der Eltern an Marx o.D. MEGA I² S. I $89 \mathrm{f}$.

2 Marx und seine Geschwister waren 1824 getauft. Die Mutter hatte ihre Taufe, die im September 1825 erfolgte, mit Rücksicht auf ihren Vater bis nach dessen Tod verschoben. Im Brief des Schwagers Schmalhausen an Marx vom I 2.X.' 47, im Nachlass, wird „notre tante Jeannette" erwähnt, offensichtlich eine Schwester der Mutter.

3 Paris I 844, S. 17. Darauf bezieht sich J. Saks' Anspielung im Marx-Aufsatz von I 908, Soc. Opstellen S. 9. Aber es war nicht Marx' erster Aufenthalt in Holland.

4 Vermutlich eine teilweise gesetzte, aber unveröffentlichte Broschüre über „deutschen Jammer", über die kleinlichen politischen Verhältnisse Deutschlands. S. G. Mayer, Friedrich Engels I S. 263. 
ob er ihm in späteren Jahren noch begegnet ist; jedenfalls besuchte er ihn im November desselben Jahres in Paris. ${ }^{1}$ Auch mit dem Schwager Schmalhausen in Maastricht stand Marx von Brüssel aus in Verbindung. Marx war zur Ordnung seiner finanziellen Verhältnisse in Maastricht und Zaltbommel ${ }^{2}$, und der Schwager besuchte ihn in Brüssel. ${ }^{3}$ Marx erhielt von ihm ein Darlehn, und der Schwager führte auch mit der Mutter die Verhandlungen über die Auszahlung des väterlichen Erbteils. ${ }^{4}$ Dies wurde ihm im Januar I 848 in Höhe von 6000 Francs ausgezahlt; aussetdem wurde ihm der Betrag von i 200 Talern, den er der Erbmasse schuldete, erlassen. ${ }^{5}$ Die Überweisung jenes Betrages hatte ein Nachspiel, in das auch die Mutter verwickelt wurde. Die Brüsseler Polizei interessierte sich für Herkunft und Verwendungszweck des Geldes und liess Frau Marx vom Staatsprokurator in Trier darüber vernehmen. Dieser gab die Auskunft, Frau Marx' Vermögensverhältnisse seien so, dass sie über einen solchen Betrag verfügen könne; der Sohn habe sie seit langem um die Auszahlung des Erbteils gebeten, das dem Unterhalt seiner Familie diene; einen weiteren Wechsel von 400 Francs habe sie nicht dem Sohne, sondern ihrem Schwager in Bommel geschickt. ${ }^{6}$

Die nächsten Zeugnisse für die Beziehungen der Familien Marx und Philips bilden die hier abgedruckten Briefe I bis 7 aus den Jahren 1853-1854. Die Briefe wurden aufgenommen, weil nur sehr wenig Briefe der Familienangehörigen von Marx bekannt sind. ${ }^{7}$ Es sind sechs Briefe der Mutter und der Schwestern Louise und Emilie nach Zaltbommel sowie ein Brief Jenny Marx' an Nannette Philips, die damals auch schon persönlich miteinander bekannt gewesen sein müssen. Jene Briefe sind schöne Zeugnisse jüdischen Familiensinnes, voller Anhänglichkeit und Fürsorglichkeit für die Mutter und ebenso für Onkel und Tante; im Stile der Zeit sind sie sehr, oft gar übertrieben gefühlvoll, die der Schwester Emilie zeigen dabei viel Witz. Vor allem bei der Mutter tritt eine Neigung zum Klagen hervor. Ihre Briefe bestätigen die Tatsache, dass die deutsche Sprache ihr nicht geläufig war; um so auffallender ist es, dass sie den holländischen Verwandten

1 Engels an Marx 23.-24.XI.'47: „Dein Vetter Philips war heute morgen bei mir.”

2 Engels schreibt ihm am 28. IX. '47 dorthin: „Mach nun Deine Geldgeschichten so rasch wie möglich ab und komm wieder her.... Nur regle zuerst Deine Geldgeschichten." 3 Schmalhausen an Marx I 2.X.' 47.

4 Ebda.

- "Il a été convenu, que la somme de Thaler 1200 , que tu dois à la masse, ne te sera pas portée en compte." Ebda. Diesen Betrag wird Marx vor 1843 von der Mutter gegen die Anerkennung erhalten haben, dass er zu ihren Lebzeiten kein weiteres Recht auf das Vermögen habe. Marx an Ruge 25.I.'43, MEGA I² S. 294.

- L. Somerhausen, L'Humanisme agissant de Karl Marx, Paris 1946, S. 244 f. Die Antwort aus Trier dort teilweise im Faksimile.

2 MEGA I'. 
deutsch schreibt. Wir erfahren, dass die Mutter die Übersiedlung nach Zaltbommel plant, eine Absicht, die vermutlich durch den Tod der Schwester vereitelt wurde. Es werden Nachrichten über Familienereignisse und alltägliche Dinge ausgetauscht. Die Kinder waren oft $\mathrm{zu}$ Besuch in Zaltbommel gewesen, und Onkel und Tante werden in Trier erwartet. Sie sind ,in Liebe und Güte unerschöpflich" für die Trierer Angehörigen. Aus alledem geht hervor, zumal diese Briefe aus wenigen Monaten stammen, dass wahrscheinlich ein reger Briefwechsel zwischen den beiden Familien bestand.

Marx' Beziehungen zur Mutter erschöpften sich, wie man weiss, in der Erledigung finanzieller Angelegenheiten. Diese bildeten, scheint es, auch den Hintergrund und jedenfalls den Anlass zu einer Intensivierung seiner Beziehungen zur Familie Philips. Der Weg zum Onkel führte über die Mutter; denn Lion Philips war ihr Vermögensverwalter, ohne dessen Rat sie keine Entschlüsse fasste, und er war schliesslich auch ihr Testamentsvollstrecker. Marx' erster Brief an Lion Philips stammt aus dem Jahre $186 \mathrm{r}$; aus den soer Jahren liegen keine direkten Äusserungen vor. Aber aus der Korrespondenz mit Engels ist es bekannt, dass Marx in den Zeiten der Not von Engels, wenn er selbst nicht helfen konnte, an die holländischen Verwandten verwiesen wurde, und dass Marx dann stets den Blick nach Trier und Zaltbommel richtete. Wir registrieren kurz die Bemühungen um Hilfe bei Mutter und Onkel; leider liegen aus den soer Jahren keinerlei Zeugnisse für elne andersartige Verbindung zwischen ihnen vor. $\mathrm{Da}$ nun Mitteilungen der Mutter an Marx fehlen, kann nur aus seinen eigenen Äusserungen das Verhalten der Mutter erschlossen werden. Es dürfte nicht zuletzt auf die Lückenhaftigkeit der biographischen Quellen zurückzuführen sein, dass die bisherige Auffassung vom Verhalten der Mutter zu Marx einer Korrektur bedarf.

Schon im Sommer I 850 hatte Marx mit der Mutter abgemacht, dass er seine finanziellen Angelegenheiten mit dem Onkel Philips regeln werde, zu welchem Zweck er selbst nach Zaltbommel reisen wollte. $\mathrm{Da}$ jedoch im jenem Sommer zwei Kinder des Onkels heirateten, verschob er die Reise. ${ }^{1}$ Es ist nicht bekannt, ob Marx im Laufe des Jahres den Onkel besuchte. Anfang r8 5 I hören wir über die Mutter: "Sie macht alles von Bommel abhängig. Ich werde wahrscheinlich den coup de désespoir riskieren müssen" 2, nämlich selbst nach Bommel zu reisen. Auf die ultimative Drohung, er werde Wechsel auf die Mutter ziehen, falls sie nicht bis zu einem bestimmten Termin antworte, und falls sie nicht zahle, nach Preussen gehen und sich verhaften lassen,

1 Marx an Karl Blind 17. VII. 'so. Intern. Review for Social History, Vol. IV, Leiden I939, S. 157 .

2 Marx an Engels 8.III.'s I. 
wandte sich die Mutter an den Schwager Philips, erhielt aber nicht rechtzeitig Antwort. Marx hält das Ultimatum aufrecht ${ }^{1}$, - aber er ging nicht nach Preussen. Sollte er also Geld bekommen haben? Ein Jahr später klagt er, die Mutter habe das versprochene Geld noch nicht geschickt ${ }^{2}$ und trotz ihres Versprechens nichts von sich hören lassen ${ }^{3}$; ein halbes Jahr später schreibt er wieder und „denkt, dass das wenigstens etwas helfen wird" 4, - wie kann er das denken, wenn die früheren Versuche erfolglos waren? Zwei Jahre später, 18 54, kommt Marx zu der Úberzeugung, dass mit der Mutter nichts zu machen sei, bis er ,ihr direkt auf dem Hals" zitze. ${ }^{5}$ Danach hören wir einige Jahre gar nichts über die Beziehungen ${ }^{6}$, bis im Jahre 1858 eine Schuldenlast von $£$ r 20 zu decken ist. Engels kann durch gewagte Manipulationen gut die Hälfte aufbringen, und er drängt Marx: „Ich glaube, es wäre an der Zeit, dass Du einen Versuch bei Deiner Alten oder irgend einem Holländer machtest.... Du musst wirklich hier etwaige Rücksichten - s'il y en aurait - beiseite setzen und einen coup versuchen. Es handelt sich darum, noch ca. $\mathfrak{E}$ so aufzutreiben, und ich sehe absolut nicht, wie sie anders als durch Deine Verwandten beigebracht werden können." 7 Als die Mutter dann ein Bild der dreijährigen Eleanor erhalten hatte, kam ein Brief, in dem sie "möglicherweise in einigen Wochen eine Zusammenkunft" mit derm Sohne ankündigte. ${ }^{8}$ Drei Wochen später: „Es ist möglich, dass sie ihr Geld herausrückt, wenn sie glaubt, meine Erbschaft sei von Obrigkeit wegen bedroht. Es ist aber auch möglich, dass sie - da sie mir ihr Testament zu machen scheint - dann alles unter die Obhut des Holländers stellt, was mir keineswegs zusagt." 9 Vom 18 . August bis 2I. September ist eine Lücke in der Korrespondenz mit Engels, und es ist nicht unmöglich, dass Marx in diesen Wochen die Mutter in Zaltbommel getroffen hat; denn an jenem Tage kann er Engels mitteilen, es seien Aussichten vorhanden, dass er mit Hilfe seiner Mutter die häuslichen Verhältnisse ganz regeln könne. ${ }^{10}$ Engels ist entzückt von dieser Aussicht; 11 aber schon am nächsten Tage teilt Marx ihm mit, die Mutter sei plötzlich ,in unerklärliches Stillschweigen gesun-

1 An Engels 3 r.III.'sr.

2 An E. r8.II.'s2.

3 An E. 27.II.'s2.

1 An E. 9.IX.'s2.

- An E. 13.IX.54.

- Jenny Marx hatte von September 1855 bis September 1856 ca. \& 250 als Erbteil ihres Onkels und ihrer Mutter erhalten. S. „Chronik" S. I 55, 159 f.

7 An Marx 16.VII.'s8.

8 An Engels 20.VII.'s8.

- An E. 8.VIII.'s8.

10 An E. 21. IX.' 5 8.

11 An Marx 7.X.'58. 
ken", und auf Engels' nochmalige Anfrage ${ }^{1}$ antwortet er, die Mutter habe einen abgeschmackten Brief geschrieben, offenbar intrigiere man gegen ihn, und er verdächtigt die Schwester, die "rationellen intentions" der Mutter durchkreuzt zu haben. ${ }^{2}$ Anfang I 859 kommt der Schwager Juta zu Besuch - er besuchte auch Engels in Manchester -, und da er auch nach Trier gehe und wichtig für die Transaktion mit der Mutter sei, müsse er anständig empfangen werden. ${ }^{3}$ Alle diese Äusserungen erwecken den Eindruck, dass Marx die ganzen goer Jahre hindurch von seiner Familie im Stich gelassen worden sei, und auf ihnen beruht die Darstellung der geizigen Mutter, die in der Literatur immer wieder auftaucht.

Danach finden sich fast zwei Jahre keine Äusserungen über Trier und Zaltbommel; aber in dieser Zeit hat Marx ,wiederholt grössere Vorschüsse" vom Onkel erhalten. ${ }^{4}$ Ende 1860 waren seine finanziellen Verhältnisse so unhaltbar, dass er meint: „Unter den jetzigen Verhältnissen wäre es scheinbar passend, meiner Alten zu schreiben", aber seit der Verheiratung der jüngsten Schwester mit J. Conradi "hat aller intercourse infolge einiger Bemerkungen meinerseits aufgehört." $5 \mathrm{Da}$ die ohnehin geringen Einkünfte von der New York Tribune in dieser Zeit halbiert wurden, - nach einem Jahre hörte die Mitarbeit überhaupt auf, - und Engels in dieser Zeit nichts tun konnte, entschloss Marx sich überraschend zur Reise zu seinem Onkel nach Zaltbommel. 6 Er war sicher, vom Onkel Geld zu bekommen; denn er zog einen Wechsel von $£ 20$ auf Lassalle auf sechs Wochen Sicht; den Betrag wollte er von Holland schicken oder selbst nach Berlin bringen. ${ }^{7}$ Er trieb einiges Geld von Engels auf und reiste, nachdem er sich bei Freiligrath erkundigt hatte, wie es mit dem Passzwang in Holland stehe ${ }^{8}$, mit falschem Pass auf den Namen Bühring ${ }^{9}$ nach Holland. Vom 28. Februar bis 17 . März war Marx in Zaltbommel, vom 18. März bis ca. I2. April Gast Lassalles in Berlin, dann in Elberfeld, Köln, Trier, Aachen, wieder in Zaltbommel, Rotterdam, Amsterdam und traf am 29. April wieder in London ein. Da der Onkel

1 An M. 21.X.'s8.

2 An Engels 29.X.'s8, 24.XI.'s8.

3 An E. 15.II.'59.

4 Marx an Lassalle 7.III.'6I. (Die Korrespondenz mit Lass. wird nach G. Mayers Nachlass-Ausgabe Bd. III zitiert).

5 An Engels 28.XI.'6o. Die Schwester war seit I 859 verheiratet.

6 An E. 14.II.'6r : „Ich bezwecke nach Holland zu gehen, um meine hiesigen Angelegenheiten, die mir sonst über den Kopf wachsen, in Ordnung zu bringen. Dazu bedarf ich zweierlei, Pass und Geld, und beides werde ich schon irgendwie auftreiben."

7 An Lassalle is.II.'6r.

8 Marx an Freiligrath 7. II. '6r. MEGA, russisch, Bd. XXV S. $37^{8} \mathrm{f}$.

9 Marx an Engels 27. II. '6r. K. J. Bühring, ein in London lebender Tischler, war Mitglied des Kommunistenbundes gewesen. 
als Bankier Geldsachen natürlich auf seine Weise behandelte, musste geschickt zu Werke gegangen werden. Die Verhandlungen waren nicht leicht, wie Jenny Marx' Darstellung zu entnehmen ist: „Infolge aller dieser Geschichten fasste nun Karl den Entschluss, einmal einen Raubzug nach Holland, ins Land der Väter, des Tabaks und des Käses zu machen. Er will sehen, ob er seinem Onkel einige Spezies ablocken kann... Am Sonnabend exhielt ich den ersten Brief mit einigen Hoffnungen und sechzig Gulden. Natürlich geht solche Geschichte nicht schnell; es muss laviert, diplomatisiert und gehörig gemanaget werden." 1 Marx ging also mit Überlegung zu Werke, und er schaltete Lassalle, dessen Freundschaft er übrigens wiederholt in den Briefen an die Verwandten erwähnt, in seinen strategischen Plan ein, indem er ihm genaue Anweisungen gab: „Du weisst, dass ich hier mit meinem Onkel (der das Vermögen meiner Mutter verwaltet und in frühern Zeiten mir öfter bedeutende Vorschüsse auf mein Erbteil gemacht) schwierige Geldverhältnisse in Ordnung bringen will. Der Mann ist zäh, hat aber viel Eitelkeit auf mein Schriftstellertum. Du musst daher in Deinem Brief an mich von dem Erfolg (lucus a non lucendo) meiner letzten Schrift gegen Vogt, von gemeinschaftlichen Zeitungsplänen und so fort sprechen, überhaupt Deinen Brief so einrichten, dass ich dem Herrn Onkel 'das Vertrauen' schenken kann, ihm den Brief mitzuteilen. Dazu musst Du nicht unterlassen, einiges über Politik mitzuteilen. Vous m'entendez, mon cher." 2 Der Onkel gab \& r6o. ${ }^{3}$ Näheres darüber erfuhr wieder Lassalle: Der Onkel habe $£$ I $5 \circ$ bar gegeben zur Zahlung der Anfang Mai fälligen Wechsel und versprochen, in einigen Wochen einen weiteren Wechsel nach London zu schicken. ${ }^{4}$,So habe ich einliegende $£ 20$ ditto einiges Geld für das Haus, und eine dritte Summe zur Rückzahlung verschiedner kleiner Anleihen in Deutschland einstweilen bei meinem Vetter aufgepumpt." $5 \mathrm{Da}$ Lassalle die Rückzahlung eines weiteren Betrages von $£$ Io verlangte, entschuldigte Marx wiederholt seine Zahlungsunfähigkeit mit der Genauigkeit des Onkels in Geldsachen.6

1 Jenny Marx an Louise Weydemeyer I 1. III. '61. Karl Marx. Eine Sammlung von Erinnerungen und Aufsätzen. Zürich 1934, S. ז08.

2 Marx an Lassalle 7. III. '6r.

${ }^{3}$ Marx an Engels 7. V. '6r.

4 S. auch M. an E. 9. VI. '6I : „Anfang Juli bekomme ich wieder einiges Geld."

5 An Lassalle 8.V.'6r. G. Mayer vermutet Jacques Philips, da dieser in London zu Besuch gewesen war.

- An Lass. 29.V.'6r. „Die Sache ist mir sehr fatal; aber mein Onkel, wie solche alte Herren sind, während er im ganzen seinem Versprechen nachkommt, tut es wenigstens mit Hindernissen für mich.” An dens. II.VI.'61 : „Du weisst, dass ich unangenehm überrascht wurde dadurch, dass mein Herr Onkel den auf mich laufenden Wechsel gezahlt, die mehr ausbedungene Summe aber für some months later! vertagt hat. Und doch musste ich lachen darüber, weil die Wendung so echt holländisch." 
Das weitere Ergebnis der Reise war die Vernichtung „einiger früherer Schuldscheine" in Trier, die Marx der Mutter ausgestellt hatte; er war mit dem Ergebnis der Reise sehr zufrieden. ${ }^{1} \mathrm{Da}$ die obenerwähnte Schuld von I 200 Talern bereits gestrichen war und die 6000 Francs das väterliche Erbteil darstellten, so muss es sich bei diesen neuen Schuldscheinen um Darlehn von unbekannter Höhe gehandelt haben, die Marx während der letzten zehn Jahre erhielt. Er hat sie von der Mutter direkt erhalten oder durch den Onkel Lion Philips; vermutlich von beiden. Die Aussicht, dass die Mutter ,alles unter die Obhut des Holländers stellt", sagt ihm I 858 keineswegs zu; er hielt es also wohl für leichter, von der Mutter als vom Onkel Geld zu erhalten. Wie Marx an Lassalle schrieb, hat er öfter bedeutende Vorschüsse vom Onkel erhalten, und diesem dankt er im ersten Brief nach der Rückkehr nach London "für die grosse Freundschaft”, die er ihm ,von neuem bewiesen" hat. Hierdurch wird die Vermutung bestärkt, dass Marx schon früher zur Regelung seiner Verhältnisse in Zaltbommel war, wenn auch in der sonstigen Korrespondenz nichts darüber zu finden ist.

Am Tage nach der Ankunft in London kündigte Jacques Philips seinen Besuch für den folgenden Tag an. ${ }^{2}$ Er blieb vom x. bis 5. Mai. Der Zweck des Besuchs war eine politische Diskussion, während Marx vermutete, dass Jacques nur „seine verschiedenen Cousinen kennen lernen wolle." 3 Jenny Marx gab eine Schilderung des Besuchs: „Da gab es alle Hände voll zu tun. Das kleine Flüchtlingshäuschen musste rasch zum feierlichen Empfang des Gastes zurecht gestutzt werden, und das würdige Ehepaar musste sich in die höheren Regionen des Hauses zurückziehen, um dem Fremden das sogenannte Staatsschlafzimmer (Rokokostil c'est à dire bric à brac) einzuräumen. Mittwoch war unseres süssen dunkelaugigen Jennychens i 7 . Geburtstag - und das war ein rechter Freudentag! Da wurde gesiedet und gebraten und flott gelebt und getanzt, gesungen und gesprungen. Die drei letzten Tage der Woche wurden zu Streifereien durch London benutzt, Kristallpalast, Museen und Parks mussten herhalten. Sonntag morgen zog der Jüngling wieder $a b$, und da fuhren wir denn wieder in das Fahrgleise des Alltagslebens ein." 4 Gleich darauf liess Marx sich photographieren für Jacques und die anderen Holländer, von denen er Photos erhalten hatte. ${ }^{5}$

Aus dieser Zeit, März bis September I86r, stammen die Briefe 8

1 An Engels 7.V.'6r.

2 Brief ro. Marx an Engels 7.V.'6r.

3 An Lassalle 8.V.'6r.

4 Jenny Marx an Lassalle 5.V.'6r.

5 An Engels ro.V.'6r. 
bis 13 . Während Marx in den Briefen an Engels ${ }^{1}$ vor allem die Berliner politischen Verhältnisse und die politische Seite des Besuchs bei Lassalle behandelt, stehen in den Briefen an die Cousine die persönlichen Erlebnisse im Vordergrund. Marx stellt sich ganz auf die Korrespondentin ein und berichtet alles, was ein junges Mädchen interessiert: ein vornehmes Haus des „Freundes Lassalle” in einer der vornehmsten Strassen, herzlicher Empfang, Theaterbesuche, glänzendes Diner zu seinen Ehren mit berühmten Leuten und - nicht zu vergessen - eine mit seinem ganzen Witz gewürzte detaillierte Beschreibung der Toilettengeheimnisse der Gräfin Hatzfeldt, sowie eine bissigere Schilderung einer anderen Dame jener Gesellschaft, daneben schliesslich auch etwas Politik. Wenn Marx seinem „little charmer” eine Unterhaltung mit der Grafin schildert, ist er selbst ein etstaunlich gewandter Charmeur. Dem Onkel berichtet Marx ausführlich über seine Erlebnisse während einiger Tage, er gibt ihm eine strategische Würdigung der Lage im amerikanischen Sezessionskrieg und versichert ihm enthusiastisch seine Verehrung für die ganze Zaltbommeler Familie. Jenny Marx dankt für den liebevollen Empfang, den die Philips dem Neffen bereiteten, und sie rechnet bestimmt mit Nannettes Gegenbesuch.

Als nach einem halben Jahre die Not wieder gross war, erhielt Marx von der Mutter als Antwort ,nichts als zärtliche Redensarten, but no cash." 2 Ende August des nächsten Jahres war August Philips für einige Tage in London ${ }^{3}$, und wahrscheinlich reiste Marx mit ihm nach Holland, um in Zaltbommel und Trier am 29. August und folgende Tage wieder sein Glück zu versuchen - vergeblich, wie er Engels mitteilt. ${ }^{4}$ Ende September schickte August Philips 2 20; ferner verschaffte er dem Vetter eine Empfehlung an seinen „RailwayFreund" 5, bei dem sich Marx um eine Anstellung in einem Eisenbahnbüro bewarb. Im Januar 1863 versprach Engels einen Teil der neuen Schulden zu decken. „Das Fehlende müsstest Du unbedingt aus dem Holländer Onkel herausschlagen. Einen anderen Weg sehe ich nicht." 6 Marx wandte sich an Lion Philips ?, und wahrscheinlich mit Erfolg, wie die Schlussabrechnung über die Erbschaft zeigt.

1 An E. 7.V. und ro.V.'6r.

2 An E. 30.X. und 6.XI.'6r.

3 S. Brief 14.

4 An E. ro.IX.'62: „Er (Borkheim) hat bisher stückweis $40 £$ gezahlt, die letzten is von diesen 40 vor I 3 Tagen, als $i c h$ abreiste. Ich wollte nämlich meinem Onkel auf den Hals steigen. Der aber war ebenfalls auf Reise auf dem Kontinent. Von da ging ich (passant par Cologne etc.) nach Trier zu meiner Alten, jedoch ohne Erfolg, was ich gleich ahnte, als Monsieur l'oncle nicht attrappierbar war."

s. Brief I5.

- An Marx 13.I.'63.

7 An Engels 24.I.'63. 
Am 30. November starb die Mutter, und Marx musste, wie er Engels schrieb, sofort wegen der Erbschaftsregelung nach Trier. ${ }^{1}$ "Ich werde auch nach Holland müssen, da mein Onkel mein monster Gläubiger."2 In Trier blieb er nur kurze Zeit; die von der Mutter hinterlassenen Papiere konnten nicht entsiegelt werden, da die holländische Vollmacht noch nicht eingetroffen war. So hinterliess er in Trier eine Vollmacht und begab sich nach Zaltbommel, ,dem hiesigen Hauptquartier, da mein Onkel erstens den bei weitem grössten Teil des Vermögens in Händen hat und zweitens Testamentsvollstrecker ist. Es wird aber jedenfalls noch 5-6 Wochen dauern, bis ich mein Geld ausgezahlt erhalte."3 Marx blieb vom 2 r. Dezember bis I9. Februar; die Zeit wurde von einer Furunkulose ausgefüllt, die von Dr. van Anrooy, Henriette Philips' Mann, behandelt wurde. Er wurde rührend versorgt: „Mein Onkel, der ein famoser alter boy ist, legt mir selbst Pflaster und Kataplasmen auf, und meine liebenswürdige, witzige und mit gefährlichen schwarzen Augen versehene Cousine pflegt und hegt mich aufs Beste." 4 Er macht mit Onkel und Cousine Spaziergänge und bittet Engels dringend um eine Photographie für das Album der Cousine; „wie soll sie an unsere Orestes-Pylades-schaft glauben, wenn ich Dich nicht einmal commovere kann, ein Photograph zu schicken"?5

Es ist notwendig, auf die Erbschaft zurückzukommen, da sich aus der Schlussabrechnung ergibt, dass Marx vor und warscheinlich auch nach I 86I von Lion Philips Beträge à conto der Erbschaft erhalten hat. Über die Höhe der Erbschaft gehen die Ansichten auseinander ${ }^{6}$, und doch steht sie genau fest. Nach dem in Marx' Nachlass befindlichen "Inventaris van de Nalatenschap" der Mutter, das zweifellos von Lion Philips aufgestellt wurde, und nach einer zu denselben Endziffern kommenden Aufrechnung, die Marx selbst vornahm, hinterliess die Mutter ein Vermögen von fl. 49.1 30,52. Davon standen fl. 7.808,90 als Guthaben auf einem Bankkonto bei Lion Philips, der Rest war von ihm in holländischen Hypotheken und Obligationen sicher angelegt. Auf jedes der vier Kinder, - Sophie Schmalhausen, Karl Marx, Louise Juta, Emilie Conradi, - entfielen fl. I 2.282,63. Davon hatte Marx erhalten nach Lion Philips' und seiner eigenen Rechnung f. 5.250.-, so dass er noch fl. 7.032,63 zu bekommen hatte. Das waren etwa

1 An E. 2.XII.'63.

2 An E. 4.XII.'63.

3 An E. 22. XII.'63.

4 An E. 27.XII.'63.

- An E. 20.I.'64.

- Rjazanov, Marx-Engels-Briefwechsel Bd. III S. XV: „Ihre Höhe lässt sich schwer bestimmen, doch war sie wohl kaum beträchtlich." Ebenso Mehring, Karl Marx, S. 3 Io. L. Schwarzschild, a.a.O. S. 3 13, gibt sie merkwürdigerweise mit $\mathfrak{1}$ I 2 an. 
$£$ 580, für Marx' Verhältnisse ein sehr hoher Betrag. ${ }^{1}$ Aus der Aufrechnung ist zu ersehen, dass Marx ausser den $f$ I 60 oder ca. $2000 \mathrm{fl}$. noch weitere Beträge, ca. $£ 270$ oder $3,250 \mathrm{fl}$., erhalten hat.

Auch sonst war das erste Halbjahr I 864 für Marx in finanzieller Hinsicht günstig. Er wurde der Haupterbe des am 9. Mai 1864 in Manchester verstorbenen Wilhelm Wolff. Die Erbschaft betrug für ihn $£ 825 .{ }^{2}$ So fielen Marx damals $£ 1400 \mathrm{zu}$, ein Betrag, wie er ihn niemals sonst besessen hat. Marx war von einer fürchterlichen Last befreit. Er hatte sich sehr früh daran gewöhnt, den „Dreck”, wenn er selbst darin steckte, „mit grosser Indifferenz zu durchwaten" 3; aber zu Anfang des Jahres, in dem die Mutter starb, war er in einer derart verzweifelten Situation, dass er sich nicht einmal mehr wie sonst "generally (nur) durch den Zynismus zu helfen" wusste. ${ }^{4}$ Er glaubte keinen anderen Ausweg zu sehen, als sich bankerott erklären zu lassen, den Haushalt aufzulösen und sich äusserst bescheiden einzurichten. Doch zog er diesen Zustand dem der letzten Jahre vor, „wobei Kopf und Herz verzehrt werden und ausserdem die kostbarste Zeit verloren geht" (mit der Beschaffung der notwendigen Geldmittel), und mir und den Kindern gleich schädliche false appearances aufrechterhalten werden." Auch das "selfesteem" werde durch eine solche Änderung der Verhältnisse, die Engels' Hilfe verhütete, wiederhergestellt werden. ${ }^{5}$ Man darf ein solches Selbstzeugnis nicht ausser acht lassen, wenn man verstehen will, welche Befreiung Marx im Sommer I864 empfand. Er ahnte wohl nicht, dass das Geld bereits in einem Jahre verbraucht sein würde, und er hat wahrscheinlich im Ernst daran gedacht, es durch irgendeine Geschäftstätigkeit zu vermehren. Jedenfalls schweben ihm in diesen Tagen des relativen Reichtums allerlei Gewinnmöglichkeiten durch Börsenspekulation vor. „Hätte ich während der letzten 10 Tage das Geld gehabt", schreibt er ${ }^{6}$, auf die Restzahlung der Wolffschen Erbschaft drängend, „so hätte ich viel Geld auf der hiesigen Börse gewonnen. Jetzt ist die Zeit, wo mit wit und very little money Geld gemacht wird in London... You will much oblige me by settling these things before July i 5 . Du entschuldigst mich, dass ich Dich plage bei Deinem charge of business, but there are very serious inte-

1 Die unten im Brief I9 erwähnte Geldsendung des Schwagers Conradi aus Trier war entweder in diesem Betrag enthalten, oder, was wahrscheinlicher ist, es handelte sich dabei um den Erlös aus Liegenschaften, etwa dem im Brief I erwähnten Garten oder Weinberg, eine Ablösung des Inventars oder dgl.

2 Laut Engels' Schlussabrechnung, Brief an Marx I I.III.'65. Rjazanov gibt „ungefähr 600 f" an. Briefwechsel III S. XVI.

3 An Engels 8.IX.'s2.

4 An E. 24.I.'63.

5 Ebda.

- An E. 4.VII.'64. 
rests at stake". Engels antwortete sogleich am folgenden Tage; aber er verlor kein Wort über diese geschäftlichen Pläne. Er kannte Marx' Unerfahrenheit in den Fragen der praktischen Wirtschaft. Tatsächlich musste er von Borkheim, Engels, Freiligrath und Lassalle über einfache Wechselformalitäten unterrichtet werden. Es ist sehr unwahrscheinlich, dass Marx imstande gewesen wäre, das Risiko der Börsenspekulation auf sich zu nehmen, wenn auch das rasche Verschwinden der $\&_{1400}$ die Vermutung eines Spekulationsverlustes aufkommen lassen könnte. Wenn Marx allerdings dem Onkel bereits eine Woche vorher ${ }^{1}$ mitteilt, dass er über $\sum_{400}$ durch Effektenspekulation in amerikanischen, "namentlich aber in den englischen" Werten gewonnen habe, - „was Dich nicht wenig wundern wird" -, so dürfen wir diesen Posten wohl als einen fiktiven Gewinn bezeichnen. Nur in dieser Zeit konnte er sich eine solche Fiktion leisten. Wahrscheinlich wollte er dem Onkel und dessen Familie, denen er sich bisher nur als armer Neffe und Bittsteller genähert hatte, imponieren, und er wusste schon, womit er ihnen imponieren konnte. Es war sein lebhafter Wunsch, in diesem Sommer die holländischen Verwandten als unabhängiger Mann, nur als Verwandter $z u$ besuchen und ihnen die Töchter vorzustellen. ${ }^{2}$ Leider kam es nicht zu dem Besuch, da im Hause des Onkels eine Pockenerkrankung festgestellt war. ${ }^{3}$

Aus diesem Jahre stammt die zweite grössere Gruppe der Briefe, Nr. I6 bis 23. Marx korrespondiert mit dem Onkel über historische und naturwissenschaftliche Themen; im Britischen Museum verschafft er sich Klarheit über Fragen, die im Gespräch erörtert wurden, und teilt dem Onkel seine Feststellungen mit. Uber politische Fragen und die Beurteilung der Geschäftslage informiert er ihn ausführlich. Die Adresse und Statuten der I.A.A. schickt er ihm sogleich nach ihrem Erscheinen, -auch die Internationale, der Marx' wichtigste politische Arbeit galt, nahm in diesem Glücksjahr 1864 ihren Anfang, - indem er mit prägnanten Worten die Bedeutung dieses Ereignisses darlegt. Natürlich berichtet er auch Familienangelegenheiten; die Teilnahme des Onkels an ihnen wurde sicherlich erhöht durch die witzigen, altklugen Briefchen der neunjährigen Eleanor ${ }^{4}$, die ihn etfreut haben werden und ihn zu Antworten veranlassten.

Zu Anfang des nächsten Jahres besuchte Marx wieder für etwa drei Wochen Holland und vermutlich alle dortigen Verwandten. Im Februar kam der Schwager Juta nach London in Begleitung Bertha Schmalhausens, einer Nichte aus Maastricht. Marx brachte sie am I9.

1 S. Brief 20.
2 S. Briefe 17, 20, 21 .
3 S. Brief 22.
4 Briefe I6 und 21. 
März zurück und blieb bis etwa 7. April. ${ }^{1}$ Aus dieser Zeit stammen die „Bekenntnisse”, eine Art charakterologischen Gesellschaftsspiels, one of those dreadful Victorian questionnaires, nennt sie Carr. Sie sind fast identisch mit der zuerst von Rjazanov mitgeteilten Liste ${ }^{2}$; nur finden sich folgende Abweichungen: als favourite occupation gab Marx dort an: Bookworming, hier: Glancing at Netjen, dann fehlen die Angaben der Lieblingsfarbe (Red) und -namen(Laura, Jenny). Der Charakter des Gesellschaftsspiels ist deutlich; es ist nicht angebracht, der Liste eine so eindringende Interpretation zu widmen, wie Rjazanov es tut.

$\mathrm{Zu}$ Weihnachten 186 , schickt Lion Philips den Marx-Töchtern $£$ s, mit denen sie ein Fest veranstalten. ${ }^{3}$ Im März geht Marx für einige Wochen zur Erholung nach Margate. Er hat das Bedürfnis, mit Nannette zu plaudern, und gibt ihr einen ausführlichen Bericht über die Sitzung des Generalrates, in der er einen Vorstoss Mazzinis abwehrte. ${ }^{4}$ An Engels schrieb er erst eine Woche später darüber. Als gegen Ende des Jahres die Not wieder gross war, richtete Marx den Blick nach Holland, - vergeblich, wie es scheint. „Ich habe noch keinen Farthing von Holland erhalten und kann also nicht darauf rechnen." 5 Er hatte sich fest darauf verlassen ${ }^{6}$; eine ,sogenannte Erbschaft" der Tante Esther Kosel in Frankfurt a.M. betrug ganze 80 Taler, und Versuche, in Deutschland Geld aufzutreiben, scheiterten.7

Da erhielt Marx am 31. Dezember I 866 die Nachricht vom Tode Lion Philips'. Während er beim Tode der Mutter nicht ein Wort der Trauer oder Ergriffenheit fand, gedachte er des Onkels: „Ich habe heute eine sehr trübe Nachricht erhalten, den Tod meines Onkels, der ein ausgezeichneter Mann war. Er starb aber schön, rasch, umgeben von allen seinen Kindern, mit vollem Bewusstsein und den Pfaffen mit feiner Voltairescher Ironie begiessend." 8 Es ist ein Verlust, dass Marx' Schreiben an die Verwandten, besonders an Nannette, aus diesen Tagen nicht bekannt sind; zweifellos gab es sie.

Damit war wohl das stärkste Band zerrissen, das Marx mit den holländischen Verwandten verknüpfte. Aber die Verbindung riss

1 Marx an Engels 4.III. und I 3.III. '65. - Jenny Marx an Nathalie Liebknecht o.D., Jenny Marx' Nachlass.

2 Die Neue Zeit, a. a. O.

3 Marx an Engels 24.III.'66.

4 S. Brief 25 .

5 An E. 26.IX. '66.

- An E. r.X.'66.

? An E. 8.XI.'66. Marx hatte sich bei Kugelmann um ein Darlehn bemüht. An Kugelmann $13 . X$. und 25.X.' 66 .

8 An E. 3r.XII.'66. Lion Philips' Familie war zu Anfang der 4ocr Jahre zum Christentum übergetreten. 
nicht ab; auch im Zusammenhang mit finanziellen Transaktionen werden die Vettern noch genannt, vor allem in der argen Not des Sommers I 868. „Die Holländer, von denen ich eigentlich nur August Philips brauchen kann, sind reisend" "; Marx schreibt nach Amsterdam und Aachen zu August und Karl Philips, um zu erfahren, ob sie zurück sind. ${ }^{2}$ Engels drängt, da es sich um einen grösseren, seine Leistungsfähigkeit übersteigenden Betrag handelt: „Du wirst Dich entschliessen müssen, nach Holland zu gehen, zu solchen Zinsen zu pumpen können wir nicht 'erfordern' ". 3 Marx schreibt wieder, aber er erhält keine Antwort: „Ich höre gar nichts von Holland und muss das Schweigen daher als absichtlich betrachten. Ich weiss in der Tat nicht, was ich anfangen soll." " Die Sache wurde dadurch geregelt, dass Engels eine Anleihe aufnahm. Gleichwohl ist es nicht wahrscheinlich, dass das Schweigen aller Vettern ,absichtlich" war, d.h. dass sie alle die Beziehungen zu Marx abbrechen wollten; denn noch Anfang 1872 bot August Philips trotz des klaren politischen Gegensatzes Marx, „dem Freund und Verwandten", wenn es not tue, auch finanzielle Unterstützung an. ${ }^{5}$ Damals war sie nicht mehr nötig; denn Ende 1868 setzte Engels dem Freunde eine Jahresrente von $£_{350}$ aus.

Danach hören wir nur noch gelegentlich von den Beziehungen. Als Marx Anfang September I 869 mit der Tochter Jenny zu Kugelmann nach Hannover fuhr, hielten sie sich einen Tag bei Karl Philips in Aachen auf. 1874, 1875, I 876 fuhr Marx nach Karlsbad, I 877 mit der Familie nach Bad Neuenahr dicht bei Aachen; bei diesen Gelegenheiten findet sich keine Spur solcher Besuche. Es ist nicht unmöglich, dass die freundschaftlichen Beziehungen zu den Vettern, wie Eleanor Marx aus der Erinnerung mitzuteilen weiss, ,till about the time of the Commune" " sich erhielten; "the uncle was then dead, and the cousins became too respectable and too frightened", ist ihre Erklärung für das Aufhören freundschaftlicher Beziehungen. Wenn August Philips 1872 eine Beteiligung an der Finanzierung der französischen Ausgabe des "Kapital" ablehnte, und zwar in sehr entschiedener Form, dann bestätigte er damit, dass auch ihn die Pariser Kommune gehörig erschreckt hatte. Der liberale Onkel würde sich nicht anders verhalten haben. Auch August Philips wird schon seit Jahren mit Besorgnis die wachsende Tätigkeit der Internationale verfolgt haben, die jetzt nicht mehr eine Sache von Arbeitervereinen, sondern eine europäische

1 An E. 23.VII.'68.

2 An E. I3.VIII.'68.

3 An Marx 14.VIII.'68.

4 An E. 12.IX.'68; auch 21 .VHI. und 26.VIII.'68.

5 S. Brief 26.

- S.S. 5r. Vielleicht entnahm sie das auch jenem Briefe August Philips'(Nr. 26), den sie aus dem Nachlass des Vaters kannte. 
Angelegenheit von grosser politischer Aktualität war. Das war die Reaktion des gesamten Bürgertums. Mochte der Vetter in seiner Jugend, - wir sahen, dass er Marx in Brüssel und Engels in Paris gerade zu der Zeit besuchte, als sie am Kommunistischen Manifest arbeiteten -, vielleicht gewisse Sympathien für ihre Bestrebungen gehabt haben, die damals für Deutschland den entschiedenen Fortschritt darstellten, so konnte er doch jetzt im „Kapital” nicht mehr nur das wissenschaftliche Werk seines "Freundes und Verwandten” sehen. Dass er eine Beteiligung an der Finanzierung ablehnt, erscheint weniger verwunderlich als Marx' Aufforderung dazu, die gar zu der Annahme berechtigt, dass seit einiger Zeit keine Verbindung zwischen ihnen bestanden habe. Anfang September des gleichen Jahres wurde die Internationale auf dem Kongress in Den Haag für Europa praktisch aufgelöst. Anlässlich des Kongresses sprach Marx in einer Versammlung der Amsterdamer Gruppe der Internationale. Es ist nicht bekannt, ob er bei diesem Aufenthalt in Amsterdam August Philips zu treffen versucht hat. Wir möchten vermuten, dass er es nicht versuchte. Ende August I 876 kommt "Carolinchen”, d.i. Caroline Schmalhausen zu Besuch nach London. ${ }^{1}$ Bei dieser Gelegenheit teilt Jenny Marx ihrem Manne mit, dass der Sohn eines Vetters verunglückt sei ${ }^{2}$; sie weiss, dass er Anteil daran nimmt. Danach finden wir nur noch eine Erwähnung des Namens. Nach Marx' Tode erhielt Eleanor Beileidsschreiben vom Vetter Carl Juta und Frau, die in London lebten, von der Tante Emilie in Trier, der Tante Sophie aus Aachen sowie von deren Töchtern Bertha und Caroline aus Den Haag ${ }^{3}$; alle diese Briefe sind so herzlich, dass nicht der Eindruck entsteht, die Verbindung zwischen den Absendern und Marx' Familie sei lange Zeit unterbrochen gewesen. Caroline Schmalhausen schreibt: „... I wrote at once to Mama and as you bade me to August Philips." Wir wissen nicht, wie er sich geäussert hat.

In Marx' Korrespondenz begegnet uns der Name Philips fast stets in Verbindung mit finanzieller Hilfeleistung. Dadurch wird der Eindruck erweckt, dass Marx die Verwandten lediglich als Quelle möglicher Hilfe gewertet habe. Aber das ist nicht der Fall. Alle jene Äusserungen sind aus Marx' „Misere” zu erklären, die oftmals die wertvollste Zeit für die Beschaffung von Geldmitteln forderte. Zur Beschäftigung mit dieser Seite der „Misere” veranlasst die Betrachtung

1 Jenny Marx an Karl und Eleanor Marx in Karlsbad o.D., Nachlass.

2 Ebda: „Du erinnerst Dich, dass Jean Philips zwei Kinder hatte, eine wunderschöne Tochter und einen sehr liebenswürdigen Sohn (der Liebling der Eltern) 22 Jahre alt. Er geht zu einem Freund, um einen Revolver zu probiren. Der Freund fragt ihn: Ist der Revolver geladen? Jean antwortet „Nein”. Der Freund zielt scherzhaft nach ihm und ins Herz getroffen sinkt der einzige Sohn todt darnieder!"

3 Sämtlich in Eleanor Marx' Nachlass. 
der Beziehungen Marx' zu der Familie Philips. Geldnot ist der ständige Refrain in Marx' Leben. Man hat sein Verhältnis zum Gelde dadurch erklären zu können geglaubt, dass man ihn als einen Bohemien

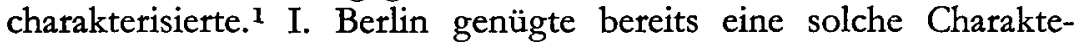
risierung nicht. ${ }^{2}$ Marx' Lebensauffassung und Lebensführung waren durchaus bürgerlich. Während in den ersten Londoner Jahren häufig proletarisches Elend in Marx' Familie geherrscht hatte, so war später, seit dem Umzug im Jahre 1856 und besonders seit dem Umzug im Jahre I 864, das unlösbare Problem, vor das er sich gestellt sah, wie eine Haushaltsführung bürgerlichen Zuschnitts von Einkünften bestritten werden könne, die nicht einmal die allerbescheidenste Haushaltsführung gestatteten. Marx fand es selbst „fabelhaft”, wie ihm in jenem Jahre das Geld in den Händen zerrann. Am 31 . Juli 1865 muss er Engels mitteilen, dass er schon seit zwei Monaten auf das Pfandhaus angewiesen sei. „Dies fact kann Dich nicht Wunder nehmen, wenn Du erwägst: I. dass ich während der ganzen Zeit keinen farthing verdienen konnte, 2. dass das blosse Abzahlen der Schulden und der Einrichtung des Hauses mich an $500 £$ kostete. Ich habe darüber pence für pence (as to this item) Buch geführt, weil es mir selbst fabelhaft war, wie das Geld verschwand... Ich wohne allerdings zu teuer für meine Verhältnisse, und ausserdem haben wir dies Jahr besser gelebt als sonst. Aber es ist das einzige Mittel, damit die Kinder, abgesehn von dem Vielen, was sie gelitten hatten und wofür sie wenigstens kurze Zeit entschädigt wurden, Beziehungen und Verhältnisse eingehen können, die ihnen eine Zukunft sichern können. Ich glaube, Du selbst wirst der Ansicht sein, dass, selbst bloss kaufmännisch betrachtet, eine reine Proletariereinrichtung hier unpassend wäre, die ganz gut ginge, wenn meine Frau und ich allein oder wenn die Mädchen Jungen wären." 3 Es ist ein Verdienst Jenny Marx', dass sie sich um die Aufrechterhaltung eines geordneten bürgerlichen Haushalts bemühte; aber Marx selbst wurde dadurch zu der unablässigen Jagd nach Geldmitteln gezwungen, die ihm immer wieder Demütigungen und Selbsterniedrigung einbrachte.

Marx hat von der Familie, von Mutter und Onkel, nicht die Mittel erhalten, die erforderlich waren; aber es trifft nicht zu, dass er von ihnen im Stich gelassen worden sei. Nicht nur die oben mitgeteilte Abrechnung zeigt es, sondern Marx' ganzes Verhältnis zum Onkel, für das seine Briefe schöne Zeugnisse sind. Gewiss handelte es sich bei den uns bekannten Transaktionen mit dem Onkel um Vor-

1 So K. Kautsky in „Der Kampf”, XVIII. Jahrg. I925, S. 331.

2 Karl Marx. London-New York-Toronto 1949, S. 180: „Marx was not a bohemian, and his misfortunes affected him tragically."

3 Marx an Engels 3I. VII. '65. 
schüsse; aber es waren schliesslich Vorschüsse auf das Vermögen der noch lebenden alten Mutter. Von ihr erhielt er nicht nur Hilfe, sondern auch ,zärtliche Worte”. Vielleicht genügten aber verwandtschaftliche Beziehungen nicht, um Marx ständig in dem Ausmass Hilfe zu leisten, wie es notwendig war; wahrscheinlich war dazu überhaupt nur Engels imstande, bei dessen Hilfeleistungen die politischen Motive von überwiegender Bedeutung waren.

Aber Marx' Beziehungen zu den holländischen Verwandten beschränkten sich nicht auf finanzielle Dinge, und das ist der für Marx’ Biographie wichtige Ertrag dieser Briefe. Zweifellos hat er auch ihnen gegenüber diplomatisiert und ,gemanaget”, wie Jenny Marx es nennt. Aber mit wem hat Marx nicht diplomatisiert? Nicht einmal Engels gegenüber glaubte er auf das Diplomatisieren ganz verzichten zu können. In Geldsachen war er dazu gezwungen, und er selbst rechnet es zu den Gefahren, die sein „selfesteem” bedrohen. Während viele Äusserungen über das Diplomatisieren mit den Philips unterrichten, zeigen nun die Briefe, dass bei Marx dieses Verhalten ganz eng verbunden sein kann mit wirklicher Zuneigung, Achtung und Verehrung; denn es kann kein Zweifel daran sein, dass diese Gefühle sein Verhältnis zu den Verwandten in der Zeit bestimmen, über die wir unterrichtet sind. Marx hat auch vor I86I freundschaftliche Beziehungen zu ihnen gehabt. Seine Briefe an Onkel und Cousine stammen aus den Jahren 1861, I 864 und 1866; immer sind sie gleich herzlich, und die Lücken in der Korrespondenz sind nur durch Verluste zu erklären. Von beiden sind leider keine Briefe an Marx erhalten, ebensowenig von Jacques Philips, mit dem Marx doch sicherlich eine Zeitlang eine politische Korrespondenz geführt hat. ${ }^{1}$ Er verehrt den Onkel als einen Mann, der auf Grund einer reichen Lebenserfahrung human, vorurteilslos und originell das Weltgetriebe betrachtet und dabei die Begeisterungsfähigkeit der Jugend sich bewahrt hat; in allen Cousinen und Vettern sieht er selbständige Charaktere, jedem schreibt er besondere geistige Vorzüge zu und allen gleichmässig eine humane Bildung. Nachdem Marx die ganze Familie kennengelernt hat, urteilt er: "Ich habe nie in meinem Leben eine bessere Familie kennen gelernt." Dem Onkel schreibt er: "I consider the two months I have lived in your house, as one of the happiest episodes of my life." Es ist kein Grund, an der Aufrichtigkeit dieser Beteuerung zu zweifeln. Es fällt Marx sehr schwer, Gefühlen der Zuneigung und Freundschaft Ausdruck zu geben. In den Briefen an den Onkel Lion Philips und die Cousine Nannette fanden sie ihren Ausdruck, und darum zählen sie, ohne persönliche Bitterkeit und Schroffheit, zu den schönsten Briefen, die Marx schrieb; beiden Empfängern und auch anderen Familien-

1 Brief ro. 
mitgliedern, - das darf auf Grund unserer fragmentarischen Kenntnis der Beziehungen gesagt werden, - stand er in einem der glücklichsten Abschnitte seines Lebens freundschaftlich nahe.

\section{i. Henriette Marx an Lion und Sophie Philips, Trier, 2.II. 1853 .}

\section{Liebe theure Geschwister}

euer lieben Brief, wahr mir sehr tröstlich, und beruhigend, den wen Ihr nicht in den plan Jutas ${ }^{1}$ eingegangen währt, wäre ich in eine peinlichen lage gerahten, es bleybt imer ein Schweerer und harter Entschlus, so wohl für Louise wie für uns, doch wen gahr keine aussicht sonst ist, so mus man zwischen zwey Ublen wählen - ich wünschte die Sache wäre schon entschieden. Die Louise reibt sich dabey auf - ich habbe schon seit Monate den garten zum verkauf anzeygen lassen, es habben sich noch fast keine liebhaber gefunden, ich denke wens einmahl heisst wir ziehen fort, dan werden wohl mehr Kaufer komen

Wen wir einmahl nach Bomel ziehen sollen, so wünscht ich wir köntten bey den Apothecker über euch Zimer bekomen das wäre mir lieber wie ein Haus en wäre mit weniger Umständen verbunden brauchten keine ganze Magd zu halten habt dank liebe Geschwister für euer Freundliches Anerbietten bey euch zu wohnen, wen man einmahl an ein ort bleyben sol hat man doch kein Ruh bis man eingericht ist. Ihr liebe Geschwister seyd in Liebe und güte für uns Unerschöpflich, und wen die Glügs Göttin, mir sonst Stiefmüterlich behandelt hat, so hat Sie mir doch noch eine quelle der Freude gelassen, in eure Liebe die nie verint, ich hoffe das euch in diesen Jahr und in alle folgende der liebe Got samt und sonders Seegnen wird - Von unsre Sophie ${ }^{2}$ erhalten wir immer gutte Nachrichten, das jüngste Kindchen gedeye seher gut, Sophie wäre beim nähren auch gesund und Robert machts auch gut, wen liebe Sophie glaubst Du das das ereynis in Achen ${ }^{3}$ für sich gehen wird, damit wir uns auf euer Komen Freuen können? Das wetter wahr bis hierhin wie bey euch immer schon man hat den ganzen wintter Blumen Sträusschen auf'm Marck bekomen können, seit ein paar tagen ist's etwas kälter, algemein wird ein gut wein jahr profezeit, es wäre nicht übel bevor wir den Berg verkauften, apropos

1 Johan Carel Juta (1824-'86), Notariatskandidat in Zaltbommel, seit 5. Juni 1853 verheiratet mit Marx' Schwester Louise (182I-'93). Beide wanderten nach Kapstadt aus, wo J. Buchändler und Verleger wurde. Sie haben Marx auf dem Wege dorthin Ende Juni 1853 und später wiederholt in London besucht. Auf Jutas Aufforderung schrieb Marx einige Aufsätze für den „Zuid-Afrikaan” in Kapstadt. M. nannte ihn einen „braven und verständigen Kerl" (an E. 14.XII.'53, 9.III.'54).

2 Marx' ältere Schwester Sophie, geb. I816, seit 1842 verheiratet mit Wilhelm Robert Schmalhausen (gest. I 862), Rechtsanwalt in Maastricht.

3 Karl und Jean Philips waren in Aachen ansässig. 
was sagt Thr zu den Nap[oleon $]^{1}$ der macht genie Streich, ich furchte er macht eimahl furschper Kriech - nu adieu liebe Geschwister gehabt euch wohl denkt hin und wieder an eure oudgrootje

HENRIETTE MARX ich grüsse den groosvatter und die lieb[en] ${ }^{2}$ kinder Herzlich.

Trier den 2 ten Febr 1853 . (Rückseite:)

HERN PHILLIPS

\section{Emilie und Louise Marx an Sophie und Lion Philips, [Trier, Frühjahr I 853 ]. \\ Liebes, bestes Sophichen und Herz Manneke!}

Dank dem Himmel, dass Ihr Euch in Versprechungen uns gegenüber eingelassen, denn Ihr wisst Euer Milchen ist eine von den sieben Plagen des Landes, die da tächt, wenn man sich nicht an der Bibel Worte hält: ,ja, ja, nein, nein, was darüber ist, das ist vom Uebel!"', so seyd Ihr wieder im Netz gefangen, und mein lieb Jüngelsken muss zu seiner Prinzessinn kommen trotz Krieg, Gevatterschaft etc. Ihr lieben Leutchen habt uns so sehr durch Eure Güte verwöhnt, dass ich mich eben so zuverlässig an Euch wende, als an unserm lieben Herrgott, und siehe da, stets wird mir Erhörung! ja, Manneke liew, seitdem Mütterchen weiss, dass Du die Sachen ein bischen in Augenschein willst nehmen, ist's ihr schon viel leichter um's Herz, Ihr seid der Polarstern, nach dem wir stets das Lebensschifflein lenken, und will die Zukunft mir auch das Aug als was umnebeln, wenn ich der Trennung von meinem mir liebsten Schwesterlein gedenke, dann richtet sich wieder der Sinn auf, träumend mich in Eurem lieben Kreise, und besonders für mein Mütterchen, die seit ihren Jugendjahren von allen Banden der Verwandtschaft losgerissen. Und so wollen wir noch der lieben Mosel ein Lebewohl zusammenbringen, uns lagern an ihren grünen Gestaden, vierbeinige Eslein haben wir zwar nicht hier, Ohmchen, aber Dein Milchen geht so sicher auf seinen Heimathbergen, wie seine Brüderlein in Ems. Maria, Joseph, was wird das eine Seligkeit werden, ich möchte mit einem kühnen Sprung in den Sommer hinein, in Onkels und Tantchens Armen. Doch Ihr lieben Leutchen, kommt kein Nettchen, kein Fritzchen mit; hätte doch so gern gehabt, dass Fritzeliemännie doch auch Trier gesehen, gesehen den Ort, wo die Kinder Israel's hinverschlagen sind worden! - Netteke hätte ich auch gerne als hübsche, erwachsene Dame den Trierer präsentieren mögen, eins davon Ohmeke liev soll wohl zu Stand kommen? So dreht der Mensch sich ewig in Vergangenheit und Zukunft herum, vergisst darüber die Gegenwart, die mir jetzt doppelt

1 Napoleon war seit einigen Monaten Kaiser; die Kriegsfurcht war allgemein.

2 Papier beschädigt. 
theuer sein sollte, und galoppiert stets durch, bis zuletzt der Rosselenker stille heisst! Doch darum nicht getröert, ich habe uns noch Allen viele Jahre beim Himmel erbeten, und als Bittstellerin bin ich zu-dringlich! Mein Briefchen ist jedenfalls keines Portos werth, deshalb beziehe ich mich auf (durchgestrichen: Louischen).

EUER ERGEBENES MILCHEN

\section{Lieber Onkel und Täntchen!}

Glücklich, unendlich glücklich hat mich Euer liebes freundliches Schreiben gemacht! Hat man einen schweren, schweren Entschluss gefasst nach manchem Kampf und Thränen, o, wie selig, wie beruhigend dann die Überzeugung, dass Die, die wir am meisten achten und hochstellen und lieben, nicht nur diesem Entschlusse nicht entgegentreten, nein, ihn auch billigen! Dank, herzlichen Dank dafür, Ihr habt diesen meinen Entschluss dadurch erleichtert - mein Herz unendlich erleichtert; ruhiger und fester gehe ich der, doch noch immer schweren Zukunft entgegen!

Mit grosser Aufregung sehe ich den direkten Nachrichten aus dem Cap entgegen - Furcht, Angst, Hoffnung, tausenderlei Empfindungen und Gedanken haben mir alle Ruhe geraubt! Oft hoffe und wünsche ich, dieser schwere Schritt möge mir erspart werden, mich von Allen, Allem, was ich liebe, was mein bisheriges inneres und äusseres Leben bestimmte - losreissen zu müssen - ach, meine theure Mutter-Schwester - Euch Alle nicht verlassen zu müssen, - aber dann wieder der Gedanke, diesen einzigen Hoffnungsstrahl verschwinden zu sehn, der mir den Besitz meines so innig geliebten Freundes sichert, wie lange vielleicht wieder getrennt zu sein, mit dieser ewigen Sehnsucht und Verlangen des Herzens, die mir allen Frohsinn, Muth, raubt, ja oft meiner Gesundheit droht; dass Alles bekämpft und reizt gar mächtig in meinem oft gar müden Herzen, und wünscht und hofft auf baldige Entscheidung, wie die Loose auch fallen mögen, dieser ewigen Aufregung zu entgehn! -

Doch mit Beschämung sehe ich, dass ich nur noch von mir geschrieben - doch Ihr seid stets so gütig und liebevoll, und gönnt gewiss meinem vollen Herzen diese Erleichterung, dass sich seiner Umgebung gegenüber fest und muthig zu zeigen sucht! Mit welcher Sehnsucht und Verlangen ich dem Kommen Juta's entgegensehe, nach einem langen, langen Jahr der Trennung, werdet Ihr begreifen, und ich bin ganz froh, dass wir einen so lieben Logée haben, der uns Alle zerstreut! Juta schrieb mir dass Du mein liebes Täntchen nach Amsterdam seiest, doch jetzt wohl wieder zurück sein wirst? Wie fandest Du das liebe, glückliche Päärchen, und ihr lieb, klein Engelchen? Gleicht's August oder Lonne, und weiss Letztere gut als Müt- 
terchen zu präsentiren? Grüsst mir die lieben, jungen Leutchen alle, besonders aber auch meinen lieben Jan und Philipin nicht zu vergessen. Adieu lieb gut Obmpichen (darf ich Dich jetzt so nennen?) und mein engels Täntchen und haltet lieb

EURE LOUISE

3. Louise Marx an Sophie Philips, Trier 31. [III. I853.]

Mein lieb, gut Täntchen!

Dein Leben, lieb Fräuchen, ist und war glücklich an Momenten und Tage des reinsten Genusses und ungestörten Glückes - denke Dir die Seligsten und Du weisst und begreifst, was mir diese 14 Tage waren, wie unendlich glücklich Dein Lousje war! Nach langem, bittren Scheiden, nach trostlosen Tagen und Nächten, so voller, warmer Sonnenschein - Frühlingswehen nach angsterregendem Sturm! Leider ist's heute der letzte 'Tag, und wollen sich Thränen und Seufzen zeigen - stosse ich sie muthig zurück - trennen wir uns doch nicht ohne Hoffnung baldigen Wiedersehn's - wohl ist's wahr, auch da giebt's tiefe, dunkele Schatten, auch da fordert meine Liebe grosse Opfer, ich soll scheiden von Allem was mir lieb und theuer - einer fernen, ungewissen Zukunft entgegen gehn. Oft wenn ich in die lieben, geliebten Züge meiner Mutter blicke dann fühle ich stechenden Schmerz im Herzen, dann möchte ich laut weinen, dass ich sie in Zukunft nicht sehen soll, nicht mehr beitragen soll zur Verschönrung und Erheitrung ihres Lebensabends - eines Lebens so voller Prüfung und Schmerz, und Losreissung von so innig Geliebtem! - Trost und Beruhigung gewährt mir dann nur der Gedanke, dass, was sie an mir verliert, Ihr ihr reichlich ersetzen werdet, dass sie in Eurer Mitte heitre und freundliche Tage noch geniessen sollt; traurig, traurig dass auch ich nicht bei Euch bleiben kann, so schön, so herrlich hatte ich mir dies einst geträumt! -

Doch Juta ist glücklich endlich einmal einen Wirkungskreis gefunden zu haben, wo er hofft mit unermüdetem Fleisse und Anstrengung gute Resultate zu erzielen, auch ich hoffe dies zuversichtlich, das lass mich Dir und nur Dir vertrauen, dass oft mein Herz sich in Angst und Furcht zusammenzieht, dass mir graut vor möglichem Nichtgelingen! Zwar Juta wird wohl überall durchkommen, und auch ich habe mir fest vorgenommen, mein Möglichstes dazu. Kann ich ja nöthigenfalls in deutscher Sprache Unterricht ertheilen, womit sich ganze Familien heute zu Tage erhalten, und sonstige kleine Erwerbsmittel; der Mensch kann viel, wo er will - und liebt, nicht wahr mein Täntchen? -

Ich wünschte nur ich wüsste sicher, wann wir gehen werden, was 
hoffentlich nicbt zu schnell sein wird, indem die zu schnelle Trennung mir doch zu schwer fiele, und dann habe ich noch nichts dazu vorbereitet. Freilich will ich dies so einfach und wenig möglich thun, doch erforderts immer Zeit. Du mein lieb Täntchen hast mir einmal angeboten Nachtkleider in Bommel für mich machen zu lassen da das Zeug dort schöner und billiger ist. Darf ich Dich dann bitten mir 6, sage sechs solche nach Deinem Muster machen zu lassen, feingestrifft und sechs Unterröcke vom selben Stoff? Es ist nun ungerne dass ich Dich damit plage, indem ich weiss, wie viel Du stets mit Andern geplagt bist, doch Mütterchen wünscht es, indem sie behauptet, hier käme ich nicht so billig dazu; willst Du mir gefälligst durch Juta bald mittheilen lassen, ob Du Gelegenheit in Bommel dazu hast, sonst kann ich's ja hier auch thun! -

Ich wünschte ich hätte Alles hinter mir, mir ist so schwer und ängstlich zu Muthe, als ginge ich einem ganz andern Sein und Leben entgegen - doch Carl und seine Liebe bleibt mir ja und ich kann nie unglücklich werden, unsre Liebe hat Kampf und Sturm getrotzt, ewiger Sonnenschein kann sie ja nicht zerstören! Nicht wahr mein Täntchen, Liebe muss Alles können und thun?

Ist auch bei Euch Frühling eingekehrt? Hier ists mild und lieblich und die letzten Tage haben wir noch herrlich genossen in unserm schönen Thal und seinen Bergen. Wir freuen uns schon darauf, wenn Ihr den Sommer kommt, es recht zu profitieren und noch für lange zusammen glücklich zu sein. Denn Ihr kommt doch Täntchen, Du musst hier sein, ich könnte nicht fort, wenn ich Mütterchen nicht in Deiner lieben tröstlichen Nähe wüsste! -

Was macht mein lieb Onkelchen, ist er noch so frisch und gesund und heiter, wie den Sommer, wo er Alles durch seinen Geist und Herz belebte? Juta musste mir immer und immer von Euch erzählen, wie und was Ihr thatet und ausführt.

Grüsse Alle herzlich von mir - Adieu lieb gut Täntchen, entschuldige mein schlechtes Schreiben - heute den letzten Tag. - Schreibe mir gefälligst bald und halte lieb

DEINE LOUISE

Mütterchen und Milchen grüssen herzlich.

4. Louise Marx an Sophie Philips, [Trier, April i853]. Mein lieb, gut Täntchen!

Juta schreibt mir, dass Du lieb Täntchen so gütig sein willst, mir die, wie ich stets fürchte, unbescheidene, Aufträge zu besorgen. Darf ich dann noch einmal näher darauf zurückkommen?

Mütterchen meint nämlich, dass wenn $\mathrm{Du} z u$ „Nachtkleidern” nocb 
nicht gekauft, Du lieber Nachtjacken mir solltest machen lassen, indem dies halb so kostspielig und in einem wärmern Lande nicht so nöthig. Auch möchtest Du so gut sein, die Unterröcke nicht so weit machen zu lassen, wie Ihr sie gewöhnlich habt, da dass Überfluss und vertheuert. Ich schicke Dir hier die Länge des Rockes von hinten und vorne. Nicht wahr lieb Täntchen $\mathrm{Du}$ bist so gut, der Näherinn zu sagen, sie einzureihen und eine Borde aufzusetzen, indem ich diese den Strippröcken vorziehe.

Mütterchen wünscht, lieb Täntchen, dass wenn Du das Zeug gekauft und den Macherlohn kennst, es zu berechnen, und uns den Preis mitzutheilen, indem wir gerne Alles zusammen berechnen und wissen wie viel ich ausgeben muss, und was noch übrig bleibt! Wirklich nur mit zagendem Herzen und höchst ungerne plage ich Dich so, da $\mathrm{Du}$ doch stets so viel zu besorgen hast !-

Und nun Gott Dank die Geschäftssachen abgemacht, und ich kann mit meinem guten Täntchen und Freun[din]chen (?) noch von etwas Anderm reden! Ach, lieb Täntchen, Du glaubst nicht, wie oft ich des Trostes, Deiner mir stets so wohlthätigen Nähe und Stärke des Geistes bedarf! Es ist eine trübe, schwere Zeit für mich - leider für Alle! Die Zurüstungen die jetzt endlich Wahrheit werden müssen, lassen diese in desto unvermeidlicheren Lichte hervortreten, sind für uns eben so viele Zeugen von unvermeidlicher Trennung. Besonders mein gut Milchen, weiss sich oft nicht zu fassen, und wir haben sie überredet, mit dem I. Mai auf 14 Tage nach Malberg zu gehen, um den Vorbereitungen zu entgehen, und sich frischen Muth in der schönen Gottesnatur zu nehmen! Glücklich werde ich sein, wenn diese Zeit überstanden, sie ist wohl noch schmerzlicher, wie kommende Wirklichkeit. Wohl will oft mein Herz sich anklagend gegen eine weise Vorsehung erheben, die solches aufgelegt, warum gerade uns so viel Kampf und Schmerz? Doch ich will nicht murren und denken und glauben, dass es ja ein gütiger Gott sein muss, dessen Wege oft dunkel, doch stets zum Lichte führend! -

Adieu mein lieb, gut Täntchen, grüsse mein engelsgut Onkelchen, die Kinder und alle Bekannte von

Deiner Dich innig liebenden

LOUISE

Milchen schreibt das Nächstemal und lässt herzlich grüssen. -

\section{Henriette Marx an Lion und Sophie Philips, Trier, 14.IV.1853.}

Liebe theure Geschwister

Schon längst hätte ich geschrieben doch fält mir's Schweer mir mit dem Schicksaal welches neuerdings Louisens betrift, mir zu versöh- 
nen. Das jezt all mein Denken und trachten sich darum dreht ist Natürlich - und es scheint das es Loos des Volks I[srael] wieder bey mir in erfülung geht das meine Kinder in alle Welt sollen verstreyt werden - in dessen siehe ich kein Ausweg, und man mus zwischen zwey ublen, das kleinste wehlen - Juta hat uns viel vergnügen gemacht und gefält immer besser je näher man Ihn kennen lernt, nun sind wir in ein ewiger Hast, alles bey zu schaffen was L[ouise] bedarf, und man gahr nichts bestimtes, über das wegehen weis. Liebe Sophie Du wirst wohl bald nach Achen gehen, und freuen uns mit der Aussicht, Dir meine liebe bald bey uns zu sehen welches auf uns alle tröstent einwirken wird nun liebe Geschwister, möchte ich bitten, eine wohnung für uns zu miehten, oben in ein Haus kein ganzes Haus, Juta Schprach davon das Du lieber Bruder ${ }^{1}$ schon d'ran gedacht hast - so werden wir den zu Schaden, ersatz mit euch lieben zusamen seyen, und können Freuden und Leyden zusamen theillen - so gut ist es mir noch nicht geworden Wen ich einsehe das der Herbst nicht gut wird, würde ich früher weg ziehen dennoch wird mir's Schweer werden von eine Umgebung wo man 40 Jahren gelebt hat abschied zu nehmen Was machen die liebe Kinder samt und sonders, es thut mir leid das lieb Jetje $^{2}$ in unsre Fusstapen treten mus, hier ist aber kein ausweg und man mus zufrieden seyn bon gres mal gres, wir wollen Hoffen, das alles Glücklich von Statten gehen mag adieu liebe Geschwister grüsst die Lieben Kinder und Grosvatter von eure euch liebende Schwester

HENRIETTE MARX

Trier den I4ten April I 853 .

6. Henriette und Emilie Marx an Henrtette van AN ROOY, [Trier, Frühjahr I854].

[vor Mevrou van Enroy].

Liebe theure jetje ich gratuliere zur glücklichen Entbindung der Himel lasse Dir ferner alles nach Wunsch gehen mit Deinen lieben Man und Kindern wir hatten es diesen winter Stil, da die Louise nicht bey uns ist, doch wollen wir Ihr die gutte tagen noch geniessen lassen, es könt Ihr gehen, wie Dir lieb jetje und dan hört für ein Zeit lang der Spas auf, doch mus du nicht verzagen hernach gehts auch wieder besser und wan man nach eignen wunsch sich vermählt darf man sich nicht beklagen. Hast du's doch viel besser wie ich's hatte, hast bey jeder Gelegenheit deine liebe Mutter bey dir, ich wahr ganz allein in ein fremdes land -

es wäre mir sehr lieb wen du mir wen deine Zeit es erlaubt einige

1 Schwager Lion Philips.

2 Henriette Philips, verheiratet mit Dr. A. van Anrooy, Stadtarzt in Zaltbommel. Uber die Andeutung s. nächsten Brief. 
Wörtchen von dir zu erhalten, und du noch an Trier denkst und an die Kölner (?) reise lebe wohl lieb jetje grüsse mir den Doctor und küsse die Kinder von Deiner Tante

HENRIETTE.

\section{Lieb, gut Jettchen!}

Mit ziemlichem Leidwesen habe ich vernommen, dass $D u$ einen dritten Sohn bekommen! Du lieber Gott, das ist nicht recht, so ganz verläugnen sein eigen Geschlecht! überhaupt, mein Liebchen, Du thätest gut, ein wenig zu sein auf Deiner Hut, man hat der Menschen genug auf Erden, und so Gott will, können ja aus Steine Menschen werden. Doch Scherz bei Seite, für Heute; wohl möcht ich einen Blick in Deine Kinderstube thun, wenn die drei kleinen Engel beieinander ruhen, ein selig Lächeln die Lippen umschweben, als seien sie von guten Engel umgeben; in Deinem lieben Auge traut, eine Thräne schaut; die glänzt noch schöner wie die Perl im Haar, da Dich umgab der Verehrer Schaar. Es tauchen in Dir auf gar schöne Wundersagen, von selbstdurchträumte Kindertagen, Du siehst in der Zukunft Zauberbild, der Liebe und der Treue Schild, von drei wackren Söhnen getragen, die Dich umscherzen in den stillern Jahren; so geht der Frühling nimmer aus, wenn Kinder spielen in der Alten Haus.

Doch jetzt auf gut Prosa, lieb Jettchen, vergiss nicht, dass Du auch ein Milchen noch in der Verwandtschaft hast, die auch einmal gern ein Wörtchen von Dir hörte; oder ist Deine Zeit zuviel in Anspruch genommen; dann trete ich mit meiner Bitte zurück. Grüsse mir Deinen lieben, guten Jan, küsse die kleinen Engel für mich und bleibe gut Deinem

MILCHEN.

7. Jenny Marx an Nannette Philips, Trier, 31 . VII. I854. Trier den 3 iten July I $854 .^{1}$

Mein liebes Nettchen! ${ }^{2}$

Der Brief des Herrn Juta, der die traurige Kunde von der Tante Sophie schwerer Krankheit brachte, hat die Mutter und Emilie sehr in Schrecken und Angst versetzt. Letztere ist ganz ausser sich und gar nicht zu beruhigen. Ihr einziger Gedanke ist gleich nach Holland zu reisen, um die liebe Tante noch zu sehen, oder auch bei dem Onkel in trüben Tagen zu weilen, mit dem sie so oft heitre und fröhliche Stunden verlebt. Die Mutter ist nicht geneigt ihr diesen Herzenswunsch zu erfüllen; und so hat mich denn Emilie gebeten, gleich

1 Jenny Marx war zur Erholung von einer Krankheit vom 8. Juli bis zum 2I. August in Trier bei ihrer Mutter zu Besuch.

2 Nannette Philips, die jüngste Tochter Lions. 
heute an Sie, mein liebes Nettchen zu schreiben und Sie recht dringend zu bitten, doch gleich nach Empfang dieser Zeilen genau zu schreiben wie es eigentlich steht und ob Emilie nicht etwa kommen soll. Ich versichere Sie, liebes Nettchen, dass ich wirklich fürchte, die Angst und Unruhe könne ihrer Gesundheit schaden. Die Mutter selbst hat sich wieder recht erholt.

Ich habe auch, seit meinem Hiersein recht traurige, angstvolle Tage verlebt. Mein liebes Mütterchen erkrankte gleich 2 Tage nach meiner Ankunft und war wirklich todtkrank, so dass ich fest glaubte, das theure Leben gehe zur Neige. Sie hat sich aber doch wieder erholt und ist schon wieder Studenweis ausser Bett und heitren frischen Geistes.

Ich hoffe sehr, dass sich die Krankheit der Tante eben so zum Guten wenden möge und wiederhole noch einmal meine Bitte um recht schnelle genaue Nachricht.

Mit den freundlichsten Grüssen, mein liebes Nettchen, sagt Ihnen heute Lebewohl

Ihre JENNY MARX.

8. Karl Marx an Nannette Philips, Berlin, 24.III.I86i. 24 March. 186r. I3, Bellevuestrasse. Berlin. My dear Cousin, (Address: Dr. F. Lassalle).

I cannot thank you enough for your precious letter which fails only in being too short, although you have acted up to the English rule of packing the best things in the smallest compass.

I arrived at Berlin on Sunday last (I 8th March), at 7 o'clock in the morning. My travel was not marked by any incident save a $6 \frac{1}{2}$ hours' delay at Oberhausen, an abominably tedious little place. Lassalle who lives in a very fine house, situated in one of the finest streets of Berlin, had everything prepared for my reception, and gave me a most friendly welcome. The first hours having been talked away and my railwayfatigue chased by some rest and some refreshments, Lassalle introduced me at once to the house of the countess of Hatzfeldt who, as I soon became aware, dines every day in his house at 4 o'clock p.m., and passes her evenings with him. I found her hair as ,,blond" and her eyes as blue as formerly, but for the remainder of her face I read the words imprinted in it: twenty and twenty make fifty seven. There were in fact wrinkles full of „vestiges of creation”, there were cheeks and chin betraying an embonpoint which, like coal beds, wants much time to be formed, and so forth. As to her eyebrows, I was at once struck by the circumstance that they had improved instead of deteriorating, so 
that art had by far got the better of nature. On later occasions I made the general remark that she perfectly understands the art of making herself up and of finding in her toilette-box the tints no longer derived from her blood. Upon the whole, she reminded me of some Greek statutes which still boast a fine bust but whose heads have been cruelly "beknappered" by the vicissitudes of time. Still, to be not unjust, she is a very distinguished lady, no blue-stocking, of great natural intellect, much vivacity, deeply interested in the revolutionary movement, and of an aristocratic laissez aller very superior to the pedantic grimaces of professional femmes d'esprit. ${ }^{1}$

On Monday, my friend Lassalle drew up for me a petition to the chief of the Prussian police for my restoration to the civil rights of a Prussian subject. On Tuesday, Lassalle himself, who is a man of extraordinary audacity, carried the petition to Herr von Zedlitz (Polizeipräsident, partisan of the Junkerpartei and the king's confident) and, what with menaces, what with flatteries - Zedlitz considering this direct appeal to himself, instead of to the subaltern authorities, as a compliment paid to his person - he has so far succeeded that to-day the ministerial paper - „Die Preussische Zeitung” - announces my return to the "fatherland". Still I have not yet received an official answer in regard to my re-naturalisation. ${ }^{2}$

On Tuesday evening Lassalle and the countess led me to a Berlin theatre where a Berlin comedy, full of Prussian self-glorification, was exacted. ${ }^{3}$ It was altogether a disgusting affair. On Wednesday evening I was forced by them to assist at the performance of a ballet in the Opernhouse. We had a box for ourselves at the side - horribile dictu of the king's "loge". Such a ballet is characteristic of Berlin. It forms not, as at Paris ,or at London, an entrejeu, or the conclusion, of an opera, but it absorbs the whole evening, is divided into several acts etc. Not a syllable is spoken by the actors, but everything is hinted at by mimickry. It is in fact deadly - dully. The scenery, however, was beautiful; you assisted for instance at a sea-voyage from Livorno to Naples; sea, mountains, seacoast, towns etc., everything being represented with photographical truth.

On Thursday Lassalle gave a dinner in honour of my return, gentlemen and ladies being invited. Among the celebrities there were the old general von Pfuel, "Schlachtenmahler" Bleibtreu, Hofrath I "Ich werde mir die als Privatkorrespondent halten in Berlin, da sie ungleich mehr politischen Verstand (abgesehen von ihren guten resourcen) hat als Lassalle". Marx an Engels 9.VI.'6r.

2 Das Gesuch wurde etwa Mitte Juni ablehnt, s.u. Brief I 2. Lassalles Beschwerde dagegen wurde vom preussischen Innenminister erst im November verworfen. Lassalle an Marx 22.XI.'6r.

3 „Die Joumalisten” von G. Freytag. An E. 10.V.'61. 
Förster (a known Prussian historiograph and formerly called the "Hofdemagog", he being a personal friend of the late king) and so forth. ${ }^{1}$ Hofrath Förster brought out a toast on my humble self. I was seated at table between the countess and Fräulein Ludmilla Assing ${ }^{2}$, the niece of Varnhagen von Ense, and the editor of Varnhagen's correspondence with Humboldt. This Fräulein, who really swamped me with her benevolence, is the most ugly creature I ever saw in my life, a nastily Jewish physiognomy, a sharply protruding thin nose, eternally smiling and grinning, always speaking poetical prosa, constantly trying to say something extraordinary, playing at false enthusiasm, and spitting at her auditory during the trances of her ecstasis. I shall to-day be forced to pay a visit to that little monster which I treated with the utmost reserve and coldness, giving her to understand by friend Lassalle that the power of attraction works upon myself always in a centrifugal direction and that, when I happen to admire a person very much, I am very apt to steal altogether out of its presence.

The state of things here is illboding for the powers that be. The Prussian Exchequer labours under a deficit, and all the old parties are in a movement of dissolution. The chamber of deputies will have to be re-elected during this season, and there is every probability that, during the process of its reconstitution, a great movement will pervade the country. This may, as my friend Lassalle thinks, be the proper moment for starting a newspaper here in the Prussian capital, but I have not yet come to a firm resolution. ${ }^{3}$ The necessity of waiting for the official answer of the authorities to my petition may prolong my sojourn beyond the term originally contemplated.

You see, my dear child, I have much seen during a few days, but still you may be sure that I always wish myself back to Bommel.

With my best compliments to yourself, your father, and the whole family, believe me always

Your most sincere admirer

CHARLES MARX.

1 Häufige Besucher Lassalles. Von Pfuel war ein Jugendfreund H. v. Kleists; I 848 preussischer Ministerpräsident. Jetzt wurde er vom Hofe „zu den Jakobinern, Atheisten usf. gezählt". An E. 7.V.'6r.

2 M. ist ihr später nicht mehr begegnet. Im April 1864 bat sie Lassalle, er möge Marx an die Rückzahlung eines Betrages erinnern. S. G. Mayer, Nachlass-Ausg. Bd. III S. 34I. 3 Marx hielt die Verwirklichung dieses Planes nicht für möglich. „A ber Du siehst, ich war in grosser Verlegenheit bei der grossen Freundschaft, die et mir bewies, mit der Sprache herauszurücken. Ich hielt mich also in allgemeiner Unbestimmtheit." An E. 7.V.'6r. 
9. Karl Marx an Nannette Philips, Elberfeld, r3.IV.i86i.

\section{To Miss Nanette}

Elberfeld, I 3 April, r 86. ${ }^{1}$

My sweet little Cousin,

I hope you have received the letter I sent you from Berlin, although you were cruel enough to leave your admirer without one single word of acknowledgement. Now, my cruel little witch, how will you be able to defend such a line of conduct? Were you not aware that a world Philisteans hemmed me in, and that half an army of antiquated beauties and detestable blue stockings, did their best to transform me into an ass? Old Circe, as you are aware, metamorphosed the companions of Ulysses into pigs. These modern Circes have so far civilized themselves as to take to the asinine line. And was it not your duty, under such circumstances, to come to my rescue? Beware that I take my revenge, and conspire with $W$ aradje ${ }^{2}$ against the tranquillity of your heart. "An's Vaterland, das theure schliess' dich an", is a very fine sentence, but, quite confidentially, I may tell you that Germany is a beautiful country to live out of it. For my own part, if I were quite free, and if, besides, I were not bothered by some thing you may call "political conscience", I should never leave England for Germany, and still less for Prussia, and least of all for that affreux Berlin with its „Sand" and its "Bildung” and „seinen überwitzigen Leuten".

At Berlin everybody who has some spirit to loose, is of course extremely anxious for fellow sufferers. If the ennui, that reigns supreme at that place, be distributed among a greater lot of persons, the single individual may flatter itself to catch a lesser portion of it. For this reason the countess Hatzfeldt, Lassalle's Egeria, tried everything to prolong my sojourn in the metropolis of tschakos without heads. Yesterday she made her last effort, and we had the following scurrilous conversation: ${ }^{3}$

She. "This, then, is the thank for the friendschip we have shown you, that you leave Berlin so soon as your business will permit?"

1 M. besuchte hier Carl Siebel, einen Verwandten von Engels. Von Berlin schrieb er ihm (28.III. und 2.IV.'6r in MEGA, russ., Bd. XXV), aus Amsterdam habe er Nachricht erhalten, dass der Vermögensverwalter der Mutter der Zahlung von $\mathfrak{E}$ roo zugestimmt habe; bzgl. der erbetenen 100-r 50 Taler rechne M. auf Siebel.

2 waratje (holl.) wahrhaftig, in der "Camera obscura" ( $\$$. Briefe 17 und 19 ) als Erstaunen ausdrückender Ausruf viel von dem Studenten Pieter Stastok gebraucht, der im Buch der Prototyp eines verlegenen und ungeschickten Courmachers ist. Hier Spitzname für einen jungen Mann (s. Brief 25).

3 Vermutlich nicht frei erfunden. Eine ähnliche Stimmung spricht aus folgender Darstellung: „Der Bursche (Lassalle) ist furchtbar pathetisch, und so blieb mir nichts übrig, als eine beständige Ironie ihm entgegenzustellen, die seine Eigenliebe um so mehr verletzte, als dadurch die Gräfin, der er sich als Universalgenie imponiert hat, bedenkliche Emanzipationsgelüste von diesem Buddha bekam". (An Engels 7.V.'6I). 
I. "Quite the contrary. I have prolonged my stay at this place beyond the due term, because your amability chained me to this Sahara."

She. "Then I shall become still more amiable."

I. "Then there remains no refuge for me but running away. Otherwise I should never be able to return to London whither my duty calls me."

She. "This is a very fine compliment to tell a lady her amability is such as to drive you away!"

I. "You are not Berlin. If you want to prove me the sincerity of your amability, do run away with myself."

She. "But I fear you will abandon me at the first station".

I. "I am not quite sure of not "leaving the girl behind me" at the next station. You know that when Theseus, having eloped with the Greek beauty, abandoned her at some station or other, there at once the god Bacchus descended from the Olymp and carried the forlorne one in his arms to the abode of eternal pleasures. Now, I do not doubt but a god is already waiting for you at the first railway station behind Berlin, and I would be the most cruel of mortals to frustrate you of such a rendezvous."

But enough of these fooleries. In true real earnest, I feel most happy in the idea of soon seeing again yourself and the whole Bommel family circle. Recommend myself to your "rival", and tell her that the deepest sentiments are the most difficult of being expressed in words. In that way she ought to interprete my silence, the respectful silence I have till now observed.

And now, my little charmer, farewell and do not altogether forget your knight-errant

CHARLES MARX.

io. Karl Marx an Lion Philips, London, 6.V.r86r.

6 Mai, $186 \mathrm{r}^{1}$

9, Grafton Terrace, Maitland Park, Haverstock Hill, London.

\section{Lieber Onkel,}

Zunächst muss ich Dir meinen innigsten Dank aussprechen für die grosse Freundschaft, die Du mir von neuem bewiesen, und die liebenswürdige Gastfreundschaft, die ich in Deinem Hause fand. Um nicht dem Verdacht der Schmeichelei zu verfallen, will ich nur ganz im Vorübergehn andeuten, welchen ausserordentlichen Genuss mir der Verkehr mit einem Manne von Deiner Erfahrung gewährt hat, der einerseits so human, vorurtheilslos und originell sich das Weltgetriebe 1 Im Original 185 r. 
anschaut, andrerseits das Feuer und den Ungestüm der Jugend sich völlig bewahrt hat.

Meine Weiterreise von Bommel verlief ganz dem ursprünglichen Plan gemässs. In Rotterdam fand ich Jacques am Landungsplatz, verplauderte ein paar Stunden mit ihm, und eilte dann noch denselben Tag nach Amsterdam, wo meine Geschäfte ${ }^{1}$ am andern Tag rasch erledigt wurden. August und seine Familie - sie war diesmal vermehrt um die Nichte seiner Frau, von Rotterdam - waren heiter und wohl. August gab mir noch speziell den Auftrag bei meiner Rückkehr nach Rotterdam Herrn Jacques etwas aufzurütteln, der plus ou moins am "Weltschmerz" leidet - eine Krankheit, die sich einfach dadurch erklärt, dass er, im Unterschied von der grossen Mehrzahl der Menschen, sich kritisch zu sich selbst verhält, und sich noch keinen ihn selbst befriedigenden festen Standpunkt in der Politik herausgearbeitet hat. Auf meiner Rückreise von Amsterdam langte ich um halb ro Uhr Abends in Rotterdam an und musste den andern Tag (Sonntag) wieder um 7 Uhr Morgens den steamer nach London benutzen. In der kurzen Zeit, die ich mit Jacques zubrachte, war es mir natürlich unmöglich alle Fragen, die er an mich richtete, zu beantworten, und auf alle Punkte, die er berührte, auch nur andeutend einzugehn. Jacques beschloss daher, nach vorheriger Besprechung mit seinen Eigenthümern, die Discussion in London fortzusetzen. Ich traf in der Welthauptstadt Montag ein und fand die ganze Familie wohl und munter. Jacques überraschte uns am vergangnen Mittwoch ${ }^{2}$ und verliess uns wieder gestern Morgen zum grossen Bedauern der Meinigen, die ihn gern länger hier gehalten hätten. Wir haben verabredet eine Art politischer Korrespondenz mit einander zu führen. ${ }^{3}$

Du wirst Dich erinnern, lieber Onkel, wie wir häufig zusammen darüber scherzten, dass die Menschenzucht heut zu Tage so sehr zurücksteht hinter der Viehzucht. Ich habe nun Deine ganze Familie gesehn und muss Dich demnach für einen Virtuosen in der Menschenqucht erklären. Ich habe nie in meinem Leben eine bessere Familie kennen gelernt. Alle Deine Kinder sind selbständige Charaktere, jedes eigenthümlich, jedes besitzt besondre geistige Vorzüge, und alle zeichnen sich gleichmässig durch humane Bildung aus.

Hier in London herrscht grosse Consternation über den Gang der Dinge in America. Die Gewaltthaten, wozu nicht nur die seceded states gegriffen haben, sondern auch einige der central oder border states - und man fürchtet, dass die sämtlichen 8 border states Partei

1 Das Umwechseln der $f$ I60, s. S. 58 .

2 Uber Jacques Besuch in London s. S. 59.

3 Von solcher Korrespondenz ist nichts bekannt. 
für die Secessionisten nehmen werden, nähmlich Virginia, Kentucky, Missouri, North Carolina, Tennessee, Arkansas, Maryland und Delaware - diese Gewaltthaten haben jeden Compromiss unmöglich gemacht. Es unterliegt keinem Zweifel, dass im Beginn des Kampfes sich die Wagschale zu Gunsten des Südens neigen wird, wo die Klasse der besitzlosen weissen Abentheurer einen unerschöpflichen fonds für eine kriegerische Miliz bildet. In the long run wird natürlich der Norden siegen, da er im Nothfall die letzte Karte einer Sklavenrevolution ausspielen kann. Die grosse Schwierigkeit für den Norden ist die question, how to get their forces to the South? An unopposed march selbst, bei der jetzigen Jahreszeit, zu is miles per day, would be something trying; aber Charleston, der nächst attaquirbare Punkt, ist 544 Meilen von Washington, 68I von Philadelphia, 77I von New York, und 994 von Boston entfernt und die drei letztgenannten Städte sind die Hauptoperationsbasen gegen den Süden. Montgomery, der Sitz des Secessionist Congress ist von denselben Plätzen 910, 1050, I 30 und I 350 miles respectively entfernt. Landmarsch scheint also quite out of the question. (Benutzung der Eisenbahnen von Seiten der Northern invaders würde blos zu deren Zerstörung führen). Bleibt also nur der Seeweg und Seekrieg über, was jedoch leicht zu Verwicklungen mit ausländischen Mächten führen könnte. Heute Abend wird sich das englische Ministerium im Unterhaus über die attitude erklären, die es bei solcher Vorkommenheit einzunehmen gedenkt.

Für mich persönlich sind natürlich die amerikanischen Ereignisse rather schädlich, da einstweilen die transatlantischen Zeitungsleser nur für ihre eigne Geschichte Aug und Ohr haben. Ich habe jedoch vortheilhafte Anerbietungen von der Wiener „Presse” erhalten ${ }^{1}$, die ich annehmen will, wenn mir einige noch zweideutige Punkte aufgeklärt werden. Ich hätte ihr von London aus zu schreiben. Meine Frau ist noch speciell gegen eine Uebersiedlung nach Berlin, weil sie unsre Töchter nicht in den Hatzfeldtschen Kreis introducirt wünscht ${ }^{2}$, es andrerseits aber schwierig wäre sie demselben ganz fern zu halten.

1 Die Beziehungen zur New York Tribune hörten im nächsten Jahre ganz auf. Das erste Angebot, für die Wiener „Presse” zu arbeiten, erhielt Marx 1857 durch Lassalle, dessen Vetter M. Friedländer Chefredakteur des Blattes war. Erst jetzt übernahm Marx die Korrespondenz aus London; im Laufe des nächsten Jahres schrieb er eine grössere Anzahl von Artikeln, die jedoch nur z. T. erschienen.

2 Jenny Marx hatte natürlich Lassalle gegenüber ihre Abneigung gegen Berlin anders motiviert, nämlich mit ihren Narben. „Ich mag mich nicht gern meinen alten treuen Freunden so zeigen, wie ich jetzt bin. Von der schrecklichen Krankheit bin ich zwar mit einem blauen Auge, aber nicht mit heiler Haut davongekommen.... Ich bin so hässlich geworden und so entstellt." (An Lassalle Anf. April 186r). 
Lassalle hat heute einen sehr freundschaftlichen Brief geschrieben. ${ }^{1}$ Er hat noch keine weitere Nachricht vom Polizeipräsidenten von Zedlitz betreffs meiner Renaturalisation erhalten. Die Collision zwischen der Polizei und dem Publicum in Berlin ist in diesem Augenblicke, wie mir Lassalle schreibt, in ein neues Stadium getreten.

Mit den besten Grüssen an Dich und die Deinigen von mir und der gesamten Familie

\section{Dein treuer Neffe}

K. MARX.

it. Jenny Marx an Nannette Philips, [London, Anfang
Mai i 86i].

Mein liebes Nettchen,

Ich habe mich sehr gefreut nach so langen Jahren einmal wieder etwas von Ihnen und dem lieben Onkel zu hören, und zwar so viel Liebes und Freundliches. Mein lieber Karl konnte mir nicht genug davon erzählen wie herzlich Sie ihn Alle aufgenommen haben und wie wohl und gemüthlich er sich in Ihrem Familienkreise gefunden. Ich wünschte wir könnten es Ihnen auch einmal bei uns so recht heimlich und gemüthlich machen. Kommen Sie recht bald zu uns. Es wird Ihnen sicher in der grossen wunderbaren Weltstadt mit ihrem riesigen Treiben und Leben gefallen und vielleicht auch in unserm stillen kleinen, ländlichen Hause. Wie schnell werden Sie das Englische sprechen lernen, unste Mädchen sprechen viel lieber englisch als deutsch und sind mit Leib und Seele true britons und hängen wie Kletten am englischen Boden. Sie waren sehr erschrocken als sie aus den deutschen Zeitungen ersahen, dass ihr ehrwürdiger papa mit seiner Familie. nach Berlin übersiedeln wolle. Ich glaubte gleich nicht recht an die deutschen canards, und denke wir werden hier noch manche jute jebratene Gans verzehren eh uns das geliebte theure Vaterland wiedersieht. Während Karls Abwesenheit hörte ich auch dass Luise und ihre Familie glücklich und wohlbehalten im Cap angekommen sind. Leider konnte ich die lieben Kinderchen gar nicht, Luise und Juta nur einmal flüchtig sehn. ${ }^{2}$ Meine Krankheit stand damals noch in dunkeln Magenta-Blüthen auf meinem Gesicht geschrieben; zum Glück mildert sich diese Purpurröthe nach und nach und werde ich hoffentlich mit

1 Lassalle tröstete Jenny Marx wegen der Narben und schrieb: „In allem, was Sie über Deutschland sagen, haben Sie theoretisch ganz recht. Aus allem folgt aber nur, dass man wo irgend möglich nach Deutschland zurückkehren muss. Denn soll dieses Land lediglich den Nachtmützen und Reaktionären überlassen werden? Das wäre freilich das geeignete Mittel, damit es nie anders würde bei uns. Und doch ist die deutsche Revolution ebenso deutsche wie europäische Notwendigkeit." (Lassalle an Jenny Marx 2.V.'6I). 2 Jutas waren im Januar zu Besuch gewesen. 
einigen blassen Narben davonkommen. Wir sind jetzt den Doctor seit einem halben Jahre nicht mehr los geworden. Lehnchen unsre treue 18-jährige Gehülfin ${ }^{1}$ erkrankte gleich nach Karls Abreise lebensgefährlich und der Doctor kommt noch immer, da sie sich sehr schwer erholt.

Seit Sonnabend gehn die Mädchen wieder in die Schule, wo sie noch Unterricht im Französischen, Zeichnen und Italienischen nehmen. Jenny schreibt Ihnen, mein liebes Nettchen, auch noch ein paar Zeilen, Laura und die kleine Ellinor lassen Sie herzlich grüssen, so wie ich Sie bitte den lieben Onkel und den Bruder Fritz ,the married man" freundlich von mir zu grüssen.

Leben Sie wohl für jetzt und kommen Sie im Sommer zu Ihrer Sie herzlich liebenden

COUSINE JENNY MARX.

I2. Karl Marx an Nannette Philips, London, i7.VIl.i86i I7 July. I86I.

My sweet little Cousin,

I hope you will not have mis-interpreted my long silence. During the first time I did not exactly know where to direct my letters to, whether to Aachen or to Bommel. Then, there came a heavy pressure of business, and during the last 2 or 3 weeks I laboured under a most disgusting inflammation of the eyes which very much limited the time I had disposable for writing or reading. So, my dear child, if I must plead guilty, there are many alternating circumstances which I trust you, as a gratious judge, will allow to influence your sentence. At all events, you would do me great wrong in supposing that during all that time one single day had passed away without the remembrance, on my part, of my dear little friend.

My Berlin affair ${ }^{2}$ has not yet been brought to a definite issue. You will remember that during my stay in the Prussian metropolis the Hohenzollern authorities seemed to yield, and even furnished me with a passport for one year. Yet hardly had I turned my back upon them, when Lassalle, to his utter astonishment, received a letter from the Polizeipräsident v. Zedlitz to the purpose that I could not be „renaturalized" because of my "politische Bescholtenbeit". At the same time the Prussian government declared that all the Political Refugees, having been absent from Prussia for more than ro years, had lost their right of citizenship, had become foreigners, and would, consequently, like all other foreigners, only be re-naturalized at the pleasure of the king.

1 Helene Demuth gehörte dem Haushalt seit 18 Jahren an.

2 Lassalle schilderte den Stand der Angelegenheit ausführlich im Brief an Marx vom I.VII.'6r. 
In other words, they declared their socalled amnesty to be a mere delusion, sham and snare. This was a point $I$ had tried to drive them to during my Berlin stay, and it was more than even the Prussian press and the Prussian chamber of deputies were able to bear silently with. Consequently, the case gave rise to bitter discussions in the journals, and to an interpellation of the cabinet in the Abgeordnetenbaus. For the nonce the ministry escaped by means of some equivocous and contradictory statements, but the whole affair contributed not a little to disillusion people in Germany as to the "new era" inaugurated by what the Berliners irreverently call the "Schöne Wilhelm". Lassalle, with his usual stubborness, tried hard to get the better of the authorities. First he rushed to Zedlitz and made him such a scene that the Freiherr got quite frightened and called his secretary for assistance. A few weeks later, Zedlitz having been removed from his post, in consequence of hostile demonstrations against him by the Berlin mob, Lassalle called upon Geheimrath Winter, the successor of Zedlitz, but the "successor" declared that his hands were bound by the decision of his "predecessor". Lassalle, lastly, caught hold of Count Schwerin, the minister of the Interior who, to escape from the violent expostulations of my representative, promised him to leave the whole case to the decision of the Berlin magistrate - a promise he is, however, not very likely to keep. As to myself, I have attained at least the one success of forcing the Berlin government to throw off its liberal mask. As to my return to Berlin, if I should think proper to go there before May i 862, they could not prevent it because of the passport granted to me. If I should delay my return, things will perhaps have so altered in Prussia, that I shall not want their permission. It is really ridiculous that a government should make so much fuss, and compromise itself so much, for fear of a private individual. The conscience of their weakness must be awful.

At the same time I had the good fortune of being honoured by the singular attention of the French government. A person at Paris whom I do not know, had a translation of my pamphlet "Herr Vogt" already in print, when an order on the part of $M$. de Persigny forbade him going on with the translation. At the same time a general warning was communicated to all the booksellers at Paris against selling the German original of "Herr Vogt". I got only acquainted with this occurence by a Paris correspondence published in the "Allgemeine Augsburger Zeitung"1.

1 Augsb. Allg. Ztg. 19.IV.'6r : „Zur Warnung für die Buchhändler wurde „Herr Vogt von Karl Marx" auf die Liste der verbotenen Bücher gesetzt, was das Erscheinen einer französischen, sehr verkürzten Verarbeitung, die sich im Drucke befindet, unmöglich macht." 
From the Gräfin Hatzfeldt I have received a letter filling I6 pages. ${ }^{1}$ Take an example of this, my dear child. She has gone - of course, in company of Lassalle - to a bathing place near Frankfurt on the Main. Thence they will proceed to Switzerland, and, after a month's sojourn there, to Italy. She feels much ennuyée and thinks herself much to be pitied, because she has no other business on hand save that of amusing herself. It is in fact a bad plight for an active, stirring and rather ambitious woman whose days of flirtation are gone by.

A Propos. I have sent from Manchester to August the two volumes of Lassalle's new juridical work ${ }^{2}$ and should like to hear whether the packet has found out its address. From Jacques I have heard nothing.

I think not, my dear child, that Mrs Marx and her daughters will find an occasion of paying this year a visit to Bommel, because the Doctor thinks a seabath during the hot season would be the best she could do for getting rid of the remainders of the terrible disease that befell her last autumn. On the other hand, I hope you will not forget your promise to visit London where all the members of the family will feel happy to receive you. As to myself, I need not tell you that nothing in the world would give me greater pleasure.

I hope, my sweet little charmer, you will not prove too severe, but, like a good Christian, send me very soon one of your little letters without revenging yourself for my too long protracted silence.

Recommend me to your father, to my friend "Jettchen", the Doctor, your brother Fritz and the whole family, and believe me always

Your most sincere admirer

CHARLES MARX.

I am quite astonished at the news of the attentat on his Prussian Majesty ${ }^{3}$, alias "Der schöne Wilhelm”. How could any person of common understanding risk his own head in order to kill a brainless ass?

13. Karl Marx an Nannette Philips, London, 24.IX.186I

My sweet little Cousin,

24 Sept. I86I.

You must excuse me for sending you to day only a few lines. The fact is that I reserve to myself the pleasure of addressing you a "real letter" in a few days. For the present, I wish only to learn, by your gracious interference, whether August has at last received Lassalle's

1 Sie hatte Marx am 14.VI.'6I mitgeteilt, dass der Berliner Polizeipräsident das Gesuch auf Wiedereinbürgerung abgelehnt habe.

2 Das System der erworbenen Rechte, Leipzig i 86r.

${ }^{3}$ Der Student O. Becker hatte in Baden-Baden ein Revolverattentat auf Wilhelm I. verübt. 
work. ${ }^{1}$ Lassalle bothers me with a new letter as to this subject, he considering of course "his work" as something awfully important. He presses me to answer him by next post, and thus I must again call upon you. You will much oblige me by informing me as soon as possible of the real state of the case.

A Propos. The book was to be sent to August from Manchester, not from London, but $I$ have been assured that it bad been sent from Manchester to Amsterdam. Of course, I don't care a fig for the whole "loss", if loss there be, since August would certainly not much miss "the work". But courtesy obliges me to make these researches.

In writing me, you will be of course so friendly to inform me at the same time of what you are doing and so forth, knowing my deep interests in all that concerns you.

My best compliments to your father and the whole family.

Believe me always your most sincere admirer

K. M.

I4. August Philips an Karl Marx, London, 25.VIII.i862.

\section{Lieber Karl!}

Auf einige Tage in London kam ich heute Dich zu sehen und finde leider weder Dich noch Deine Familie. Es wäre mir jedoch sehr lieb wenn es Gelegenheit gäbe den Besuch mit besserem Erfolg zu erneuern, - oder, was uns beiden besser conveniren möchte, Dich in der City zu treffen. Ich bleibe noch zwei Tage und reise Donnerstag ab. Bestimme mir nun irgend einen Ort zu einem Rendezvous und schreibe mir 45 Phillimore Gardens,

$$
\begin{gathered}
\text { Kensington, London, care of } \\
\text { Mr. Forbes Esq. }
\end{gathered}
$$

AUG. PHILIPS.

1 Marx hatte das Werk rezensieren wollen, Lassalle an Marx 27-28.VII.'6r, gab jedoch diese Absicht auf und liess durch Engels ein Exemplar an August Philips schicken. „Lupus [Wilhelm Wolf] hat mir sein Exemplar geschenkt zu folgender Verfügung: dass Du es nämlich schickst an meinen Vetter unter der Adresse: „A. Philips, Advokaat. Keizersgracht bij de Westermarkt. L.L. 267. Amsterdam.” Du musst natürlich L(assalle)s Zueignung an lupum auskratzen. Mein Vetter interessiert sich für theoretische Jurisprudenz.” An Engels I.VII,'6I. Am 20. Juli erkundigt er sich, ob es geschickt sei. „Letzteres mir wichtig, da ich der bons offices dieses Jünglings sehr bedarf." Am 28.IX.: "Soeben erhalte ich Brief $m$ [einer] Nichte, wonach A. Philips immer noch nicht den Lassalle erhalten hat." Am 6.XI.'6I, 25.II.'62 und 3.III.'62 mahnt er wieder dringend, da er „an besagten Vetter in Ermangelung dieser Wissenschaft nicht schreiben kann". Am 5.III. antwortet Engels, das Werk sei am 9. Oktober an den Agenten der Fa. Ermen \& Engels in Amsterdam, E. Schröder, geschickt. An Lassalle schrieb Marx 7.IX.'62 : „Mein Vetter aus Amsterdam schreibt mir, dass Dein Buch von ihrem gelehrtesten Juristen auf seine Anregung besprochen werden wird ausführlich in der Amsterdamschen juristischen Zeitschrift." 
Wo möglich wäre mir Morgen Abend, sonst am Mittwoch morgen am liebsten.

25 Aug. 62.

15. August Philips an Karl Marx, Amsterdam, 29.IX.I862. Lieber Karl, Amsterdam, 29 Sept. I 862.

Es war mir lieb zu hören, dass Du Deine Reise gut zurückgelegt hattest. Hoffen wir, dass Du den Zweck damit erreichst und es Deinen Kölner Freunden gelingt Dir eine etwas mehr sichere EinnahmeQuelle zu besorgen. ${ }^{1}$ Jedenfalls solltest $\mathrm{Du}$ nicht nachlassen meinem Railway-Freund einen Besuch zu geben. ${ }^{2}$ Er war sehr höflich, es kann nützen und keinenfalls schaden. Für Ein Mal solltest [Du] dieses Philister-raisonnement gelten lassen!

Ich hoffe sehr, dass die Gesundheit Deiner Frau und Töchter befriedigend sein wird und bedauere es sehr dass mir die Gelegenheit abging Deine Familie zu sehen. ${ }^{3}$ Glück zu Deinen patriarchalischen Aussichten ${ }^{4}$; ich hoffe doch, dass Du mich bald auch Näheres und Gutes darüber hören lässt. Ueberhaupt sollten wir uns wenigstens dann und wann einmal „becorrespondiren” wie Du sagst.

Hiebei $£ 20$.; schreibe mir gefälligst ob die Tratte Dir gehörig zur Hand kam und ausbezahlt wurde - was ich kaum bezweifle.

Der Vater ist zurück in Bommel; Nettchen blieb noch in Aachen. Uebrigens ist all right und nichts besonderes.

Grüss Deine Frau von Deinem

AUG. PHILIPS.

\section{Eleanor Marx an Lion Philips, [London, Dezember My dear uncle 18637.5}

Although I have never seen you I have heard so much about you that

1 Marx war in Trier und Zaltbommel gewesen, s. S.6o. Von dem hicr genannten Zweck der Reise ist nichts bekannt, ebensowenig ob Marx in Köln zu jener Zeit eine Einnahmequelle hatte.

2 "Es ist möglich..., dass ich Anfang nächsten Jahrs in ein englisches Eisenbahnbureau eintrete." An Engels I0.IX.'62. August Philips hat sich also schon bei seinem Besuch im August darum bemüht. „Meine schlechte Handschrift war der Grund, dass ich die Stelle nicht erhielt". Marx an Kugelmann 28.XII.'62.

3 Jenny Marx war mit den Töchtern in Ramsgate zur Erholung.

4 Vielleicht geplante Verlobung der ältesten, I 844 geborenen Tochter Jenny?

5 Der Brief Eleanors wurde von Jenny Marx einem Brief an ihren Mann beigelegt, der die Weihnachtszeit 1863 in 'Zaltbommel war, s. S. 6r. In Jenny Marx' Brief, im Nachlass, heisst es u.a.: „Ich fürchte Du bist in Bummelland (ein Ausdruck Freiligraths) eingefroren und eingeschneit... Wüsste ich Dich nicht im gesegneten Lande, so würde ich mich, namentlich in dieser Weihnachtszeit, wo "home" und „family" die parole des Tages sind, sehr, sehr verlassen gefühlt haben. So hatte ich wenigstens bei Deinem Leiden die Beruhigung Dich gehegt und gepflegt zu wissen und das half mir über vieles hinweg.... Das kleine Kind kann kaum die Zeit Deiner Rückkehr erwarten und behauptet täglich, heute kommt mein dada..." 
I almost fancy I know you, and as there is no chance of my seeing you I just write these lines to ask you how you are. Are you enjoying yourself? I am, and always do at Christmas time which I think is the jolliest in the year. I wish you a very happy new year, and dare say you are as glad to get rid of the old one as I am. I hear from papa that you are a great politician so we are sure to agree. How do you think Poland is getting on? I always hold up a finger for the Poles those brave little fellows. Do you like A. B. ${ }^{1} \mathrm{He}$ is a great friend of mine.

But I must say goodbye now, but dare say you will hear from me again.

Give my love to my cousin Nettchen and to Dada.

\section{Goodbye, dear uncle \\ I am \\ Your affectionate}

ELEANOR MARX.

17. Karl Marx an Lion Philips, London, 20.II.[1864].

London. 20 Feb. [1864]. ${ }^{2}$

Lieber Onkel,

Ich beginne mit dem Ende. Gestern about noon kam ich hier in einem sehr kühlen Zustand an, for it was devilish cold. Um so wärmer war mein Empfang und so genoss ich die von einem vollkommenen Widerspruch unzertrennlichen Freuden. Gestern und heute - en passant - waren die kältesten Tage in London. Es scheint also, dass ich berufen bin nicht nur nach Bommel, sondern auch nach London den Winter zu bringen. I wish the Prussians in Schleswig-Holstein the full enjoyment of this ,seasonable weather". If their patriotism or rather "Unterthanenbejeisterung", is not cooled down by that, then, Sir, we must give it up!

Das kleine Kind ${ }^{3}$ was quite enchanted by the really beautiful Dolly, Madame August had chosen for her. I enclose some lines on the part of the child. She did not leave off bothering myself till I had promised her to enclose also for you a letter which she pretends to be written in Chinese characters and which an English friend has sent her.

[In Amsterd] ${ }^{2}$ am fand ich die ganze Familie wohl und heiter.

1 Vermutlich A. Blanqui, der in Marx' Familie sehr bewundert wurde. Auf Grund Marxscher Informationen hatten Gräfin Hatzfeldt, L. Assing u.a. Berichte über die Misshandlungen Blanquis im Gefängnis in deutschen, italienischen und amerikanischen Zeitungen untergebracht.

2 Papier beschädigt.

3 Eleanor. 
[Da August $]^{1}$ sehr beschäftigt war, sagte ich ihm gar [nichts von] ${ }^{1}$ den Geldaffairen. ${ }^{2}$ Ich empfing Tausendguldennoten bei der Assecurantiecassa, die ich mit Jacques' Hilfe in Rotterdam zum grössten Theil in Wechsel umsezte, zum 4 ten Theil about in banknotes.

Jacques hatte während der zwei Tage, die ich in Rotterdam war, auch keineswegs bloss freie Zeit. Den einen Tag plaidirte er in einem benachbarten Städtchen, und den andern Tag hatte er einer Expertise beizuwohnen. Es schien mir überhaupt, dass er seit seiner Verlobung viel mehr als früher, ,an eye to business" hat. Ich zweifle nicht, dass er in wenigen Jahren gehörige Praxis haben wird, um so mehr, als er die Juristerei liebt. Er selbst erzählte mir, dass er fast alle faulen Processe gewinnt, und wenn er sich die Mühe giebt so was zu erzählen, kann man's auf das Wort glauben. Sehr lachte ich mit ihm über einen Mann, den er „den Clienten” par excellence nennt. Der Mann, sagte er mir, sei noch jung, und könne noch viel Vermögen in 30 J[ahren] or more verprocessiren!

Nebenbei: August hat auch ganz eigenen Glauben in die Unfehlbarkeit der Gerichte. So meinte er z.B., die Engländer verlören nichts dabei, dass ihr Prozessverfahren so kostspielig sei. Leute die nicht processirten hätten grade so viel Chance Recht zu finden als Leute die processiren. In point of fact, it seemed his opinion, that dear law is as good as cheap law, and perhaps better; and he is a fellow who knows something about such things.

August gab mir die 3 Theile der Aardrijkskunde ${ }^{3}$, und Jacques versah mich obendrein noch mit einer politischen Oeconomie (holländisch) von Vissering ${ }^{4}$, Professor zu Leiden, und mit einem Exemplar der camera obscura. ${ }^{5}$ So bin ich vollauf mit holländischer Literatur versehn. Friesisch war nicht aufzutreiben in Amsterdam, obgleich in einer Buchhandlung allein Schriften in 88 modernen Sprachen vorhanden waren. Die Negersprachen scheinen den Amsterdamern näher zu liegen als das Friesische, but man always contrives to neglect the things that are nearest to him.

Das „Sorje Oppenheim" 6, das bereits in Amsterdam viel Sensation machte, ist hier von meinen Töchtern mit Clavierbegleitung execu-

1 Papier beschädigt.

2 Lion Philips zahlte Marx die mütterliche Erbschaft aus, s. S. 6r.

3 Geographie.

4 S. Vissering, Handboek der Practische Staathuishoudkunde, Amsterdam I 860-65. Dass Marx das Werk gelesen hat, bezeugt eine kritische Bemerkung über Vissering in Das Kapital I, Moskau I932, S. 529. Zwei lange Zitate aus dem Werk sind wohl von Marx selbst übersetzt; siehe Das Kapital III, dies. Ausg., S. 349, 351 .

- Bekannter holl. Roman von Hildebrand (1839), der humorvoll das bürgerliche Leben der I 83 oer Jahre schildert.

- S. Zr. wohl beliebtes Lied. 
tirt worden, and they hope to perform it one day before their uncle.

Es hat sich hier ein grosses Convolut Zeitungen etc. aus verschiedenen Breitegraden für mich aufgehäuft, but I am firmly resolved to know nothing of politics until Monday next.

Now, my dear uncle, I bid you farewell. Despite carbuncles and furuncles, I consider the two months I have lived in your house, as one of the happiest episodes of my life, and I shall always feel thankful for the kindness you have shown me.

You will, of course, tell Rothhäuschen ${ }^{1}$ that I send him my compliments and that I regret having been forced giving battle to him.

My best compliments to the whole family, especially Jettchen, Dr Anroy and Fritz. Mrs. Marx and the girls send also their compliments. Please to give the enclosed lines to Netchen.

Yours truly

CHARLES M.

18. Karl Marx an Lron Philips, London, [Ende März i864]. I, Modena Villas, Maitland Park,

29 Maart ontvgen 30 do antwd 4 April ${ }^{2}$ Haverstock Hill, N.W. London. Lieber Onkel,

Ich unterstelle, dass Ihr schon oder noch zu Aachen seid, und richte daher diese Zeilen dahin. Wolltet Ihr auf gutes Wetter warten, so hättet Ihr bis jetzt zu Bommel bleiben müssen. Hier wenigstens war der März quite abominable, einen oder zwei schöne Tage ausgenommen, kalt, nass, und jeden Augenblick wechselnd. Es ist dies vielleicht ein Grund warum ich die Verdummelinge ${ }^{3}$ von Furuncles bis $\mathrm{zu}$ diesem Moment noch nicht los bin. Ich fluche drauf, aber verstohlen.

Little Eleanor hat seit zwei Tagen einen etwas heftigen Husten, und dies hindert sie Dir zu schreiben. Sie trägt mir jedoch viele Grüsse an Dich auf, und, in regard to the Danish Question, begs me to tell you, that "she don't care for such stuff", and that "she considers one of the parties to the quarrel as bad as the other, and perhaps worse."

Die Schwierigkeit die preussische Politik zu verstehn, entspringt blos aus dem Vorurtheil der Menschen, das ihr ernste und weitaussehende Zwecke und Pläne unterschiebt. In der Art ist z.B. auch die Mormonenbibel sehr schwer zu verstehn, weil nämlich kein Funke von Verstand darin ist. In erster Instanz bezweckte Preussen die Armee populair zu machen, ein Zweck dem schon 1848 die Schleswig-

1 Pfarrer Roodhuyzen, später Nannette Philips' Gatte.

2 Bemerkung von Lion Philips.

3 Deutsche Schreibweise eines holländischen Wortes: verfluchte Kerle. 
Holstein Campagnen dienen mussten. Zweitens galt es der deutschen Freischarerei, Democraten und den Kleinstaaten das Terrain zu versperren. Endlich sollen Preussen und Oestreich den Daenenkönig, der mit ihnen unter einer Kappe spielt, durch pressure from without befähigen die Daenen zu gewissen Concessionen nach aussen und innen zu zwingen. Oestreich konnte Preussen natürlich das Rollenspielen nicht überlassen und benuzte zugleich die Gelegenheit eine genauere Allianz für other peripeties mit ihm zu Stand zu bringen.

Am I 2ten April kommt die Conferenz ${ }^{1}$ in London zusammen. Im alleräussersten Fall wird sie Personalumion von Schleswig und Holstein mit Daenmark beschliessen, vielleicht noch weniger, keinenfalls mehr. Wie wenig ernst trotz Pulver, Blei und Blutzapfen die ganze Affaire ist, siehst Du schon daraus, dass weder Preussen und Oestreich an Daenemark, noch Daenemark an Preussen und Oestreich den Krieg erklärt haben bis zu diesem Augenblick. Es giebt kein besseres Mittel um Sand in die Augen zu streuen als Armeen marschiren, Pferde trampeln und Kanonen böllern zu lassen.

Despite all that, mögen serious conflicts be imminent. Bonaparte sieht sich fast gezwungen seine troupiers wieder ein Exportgeschäft in „Freiheit” machen zu lassen, in Folge der grossen disaffection, die zu Paris nicht nur vorhanden ist, sondern in den Wahlen provocirend die Stirn zeigt. Und die Hände von Preussen haben ihm diesmal den Weg gebahnt.

Garibaldi's Reise nach England und die grossen Ovationen, die er hier from all sides empfangen wird, sind blos, or sollen wenigstens sein, Ouverture to a new rising against Austria. Letztres, als Alliirter der Preussen in Holst. Sch. [Schleswig-Holstein], und Alliirter der Russen durch den Belagrungszustand in Galizien, hat seinen Feinden das Spiel sehr erleichtert. Eine neue heilige Allianz, mit den gegenwärtigen Zuständen in Polen, Ungarn, Italien, der Volksstimmung in Deutschland, und der ganz veränderten Stellung Englands, würde selbst Napoleon le Petit befähigen den Grossen zu spielen. Fortdauer des Friedens wäre in diesem Augenblick das Beste, denn jeder Krieg schiebt die Revolution in Frankreich auf.

Gott verdumme! if there be anything more stupid than this political chessboard!

Ich hatte eigentlich vor Dir noch über zwei Dinge zu schreiben, die römische Division und die Finsterkeit im Weltraum. Da es aber dunkel wird, das Papier zu Ende geht, und Postschluss vor der Thüre steht,

1 Konferenz der europäischen Mächte zur Behandlung der schleswig-holsteinischen Frage; sie wurde auf den 20. April verschoben und dann am 25. April offiziell eröffnet. Am 9. Mai wurde ein Waffenstillstand geschlossen, dann scheiterte die Konferenz, und am 26. Juni begannen die Feindseligkeiten wieder. 
muss ich für diesmal schliessen mit den besten Grüssen der ganzen Familie. Ditto an Karl und Gattin, Jean enz.

Dein treuer Neffe

K. MARX.

19. Karl Marx an Lion Philips, London, I4.IV.i864. 14 April. 1864.

Antwd $12 \mathrm{Mei}^{1}$

I, Modena Villas, Haverstock Hill. N.W. London.

Lieber Onkel,

Ich hoffe, dass die Hustenattaque den Weg allen Fleisches gegangen ist. Seit ein paar Tagen hat sich kein neuer furuncle bei mir gezeigt und mein Doctor meint, dass ich das Zeug nun definitiv los bin. Es wäre in der That an der Zeit. Die Sonne scheint endlich durchzubrechen. Es weht aber noch ein böser Wind vom Osten. Eleanor's Husten ist weg. Dagegen hat ihre Schwester Jenny einen sehr bösartigen cough, [der erst] ${ }^{2}$ mit Windwechsel verschwinden wird.

Ehe ich Deinen Brief erhielt, hatte Conradi ${ }^{3}$ mir bereits geschrieben und ich ihm geantwortet, er könne das Geld direkt hierhin schicken.

Ich hatte auf dem Museum den Boetius „De arithmetica” (Schriftsteller aus der Zeit der Völkerwandrung) über die römische Division (er kannte natürlich keine andre) nachgesehn. Es geht mir daraus und einigen andern Schriften, die ich verglichen, folgendes hervor: Mässige Rechnungen, w[ie] ${ }^{2}$ Haushaltungs- und Handelstechnungen wurden nie mit [Zahlen] ${ }^{2}$ sondern mit Steinen und anderen ähnlichen Marken auf einem Rechenbrete gemacht. Auf diesem Brete waren mehre parallele Linien verzeichnet, und hier bedeuteten einerlei Steine oder sonstige sinnliche Zeichen auf der ersten Linie Einer, auf der zweiten Zehner, auf der dritten Hunderter, auf der vierten Tausender u.s.w. Solche Rechenbretter dienten fast das ganze Mittelalter und werden heute noch von den Sinesen gebraucht. Was grössere mathematische Rechnungen angeht, so hatten die Römer in der Zeit, wo diese bei ihnen vorkommen, bereits die Multiplicationstafel oder das Einmaleins des Pythagoras, allerdings noch sehr unbequem und schwerfällig, denn jene Tafel war theils aus eignen Characteren, theils aus Buchstaben des [griech] $]^{2}$ ischen (später römischen) Alphabets zusammengesetzt. [Da die] ${ }^{2}$ ganze Division sich aber auflöst in Analyse des Dividends in Faktoren und jene Tafel zu ziemlich hohen Zahlen fortgeführt war, musste dies hinreichen um Ausdrücke wie MDXL

1 Bemerkung von Lion Philips.

2 Papier beschädigt.

3 Marx' Schwager in Trier. Uber diese Geldsendung s. S. 62. 
etc. zu zerlegen. Jede Zahl, wie z.B. M wurde einzeln zerlegt in die Faktoren, die sie mit dem Divisor bildet, und die Resultate nachher zusammen addirt. Also z.B. M dividirt [durch] ${ }^{1}$ zwei $=\mathrm{D}(500)$, $\mathrm{D}$ dividirt durch $2=250 \mathrm{u}$. [s.w.] ${ }^{1}$ Dass bei sehr grossen Rechnungen die alte Methode unüberwindliche Hindernisse in den Weg legte, sieht man aus den Kunststücken, wozu der ausserordentliche Mathematiker Archimedes seine Zuflucht nahm.

Was die „Finsterkeit des Weltallraums” betrifft, so geht diese nothwendig aus der Lichttheorie hervor. Da Farben nur erscheinen, wo Lichtwellen zurückgeworfen von Körpern, und in den $Z$ wischenräumen zwischen den Himmelskörpern weder Atmosphäre noch sonstige Körper, müssen sie pechschwarz sein. Sie lassen den ganzen Lichtstrahl durchpassiren, was nur ein andres Wort dafür ist, dass sie finster sind. Ausserdem ist aber noch der Weltraum ausserhalb der Atmosphären der Planeten etc. verdammt „koud en kil" 2, da die Stralen nur Wärme erwecken wo sie auf Körperliches stossen, weshalb es auch schon in den höhern Luftlagen unserer Atmosphäre, im Sommer wie Winter, eiskalt ist, nämlich wegen der Dünnheit, also relativen Körperlosigkeit, dieser Schichten. But

Sollte diese Qual uns quälen,

Da sie unsre Lust vermehrt? ${ }^{3}$

Wozu auch Licht und Wärme, where there is no eye to see the one, and no organic matter to feel the other? Der brave Epikur hatte schon den sehr vernünftigen Einfall die Götter in die Intermundien (i.e. die leeren Zwischenräume der Welt) zu verbannen, und in der That in diese kalten, kühlen, pechfinstren „stoffelooze wereldruimte" 4 gehören R's ${ }^{5}$, vollkommene Hünde" hin.

Dass ich ein guter Holländer geworden bin, ersiehst Du daraus, dass Jennychen schon die halbe Camera obscura, Laura grossen Theil of the first volume of the „Aardrijkskunde” durchgelesen, me docente, und selbst Eleanor „Dans Nonneken dans” und „Klompertjen en zijn wijfjen" ${ }^{6}$ auswendig kann.

Beste Complimente von the whole family an Dich, Karl, die Frau Generalin 7 enz. Mit diesem schönen Wetter wird auch Dein beau jour sicher nicht auf sich warten lassen.

Dein treuer Neffe KARL MARX.

1 Papier beschädigt.

2 kalt und frostig.

3 Aus Goethes West-Östlichem Divan, An Suleika.

4 stoffloser Weltenraum.

5 Vermutlich Roodhuyzen, mit dem Marx einen Disput über diese Fragen hatte. S. Brief 7 .

- Holländische Kinderlieder.

7 Wohl Karl Philips' Schwiegermutter; sein Schwiegervater war General. 
20. Karl Marx an Lion Philips, London, 25.VI.i864.

London, 25 Juni 1864.

Antwoord

2 August $1864^{1}$

I, Modena Villas, Maitland Park, Haverstock Hill.

Lieber Onkel,

Meinen besten Dank für Deinen ausführlichen Brief. Ich weiss, wie lästig Dir der Augen wegen das Schreiben ist und erwarte in der That nichts weniger als dass Du auf jeden meiner Briefe antwortest. Es hat mich gefreut aus Deinem Schreiben zu sehn, dass Du körperlich wohl bist und dass Deine geistige Heiterkeit selbst von den Entdeckungen des Prof. Dozy ${ }^{2}$ unerschüttert ist. Seitdem jedoch Darwin unsre gemeinschaftliche Abkunft von den Affen bewiesen hat, kann kaum noch any shock whatever ,unsern Ahnenstolz" erschüttern. Dass der Pentateuch erst nach der Rückkehr der Juden aus der babylonischen Gefangenschaft fabricirt ward, setzte schon Spinoza in seinem tractatus theologico-politicus aus einander.

Eleanor dankt selbst in beiliegenden Zeilen ${ }^{3}$ für Dein Photogramm, das so gut ist wie diese Schattenbilder überhaupt sind. Das Kind hatte mir „,ihren Brief” schon seit 3-4 Tagen auf meinen Schreibtisch gelegt.

Ich hatte Rückfälle von furuncles und bin erst seit I 4 Tagen wieder ganz frei. Da mich diese lästige Krankheit sehr am Arbeiten hinderte - der Arzt mir ausserdem angestrengte und vielstündige geistige Arbeit untersagt hatte - habe ich, was Dich nicht wenig wundern wird, speculirt theils in Americanischen funds, namentlich aber in den engl[ischen] Actienpapieren, die wie Pilze in diesem Jahr hier aus der Erde wachsen (für alle möglichen und unmöglichen Actienunternehmungen, zu einer gewissen unvernünftigen Höhe getrieben werden und dann meist zerplatzen. Ich habe in dieser Art über $400 £$ St. gewonnen, und werde jetzt, wo die Verwicklung der politischen Ver-

1 Bemerkung von Lion Philips.

2 Aus dem Brief des Onkels zitierte Marx im Brief an Engels (x6.VI.'64) folgendes: „Ein holländischer Orientalist, Professor Dozy zu Leyden, hat ein Buch herausgegeben (De Israeliten te Mecca na Davids tijd tot in de vijfde eeuw onzer tijdrekening. Haarlem I 864) zum Nachweis, dass „A braham, Isaak und Jakob Phantasiebilder; die Israeliten Götzendiener waren; einen "Stein" mit sich in der ,arke des Verbonds" herumschleppten; dass der Stamm Simon (unter Saul verbannt) nach Mekka gezogen und da einen Götzentempel gebaut und Steine angebetet habe; dass Israel nach der Befreiung aus Babylon die Legende von der Schöpfung bis auf Josua gedichtet und ferner Gesetz und Dogma zur Vorbereitung der Reform, Monotheismus, geschrieben usw." So schreibt man mir aus Holland, und dass das Buch grossen Spektakel unter den dortigen Theologen macht, namentlich weil Dozy der gelehrteste Orientalist in Holland und dazu - Professor in Leyden!"

S. folg, Brief. 
hältnisse neuen Spielraum bietet, von neuem anfangen. ${ }^{1}$ Diese Art von Operationen nimmt nur wenig Zeit fort, und man kann schon etwas riskiren um seinen Feinden das Geld abzunehmen.

In meinem Haus ist alles ziemlich wohl. Für Jennychen wünscht der Doctor ,change of air”, und wenn Du und das Schicksal nichts dagegen haben, werde ich Ende Sommer Dich mit meinen 3 Töchtern heimsuchen. ${ }^{2}$

Der Telegraph wird den resultatlosen Ausgang der Conferenz ${ }^{3}$ schon all over Europe bekanntgemacht haben. Die Einzigen, die in dieser diplomatischen Trago-Komödie ungestört ihre alten Zwecke verfolgen und meisterhaft spielen, sind les Russes. Auf der einen Seite erneuern sie die heilige Allianz, treiben die deutschen Ochsen in den Krieg, lenken dadurch die Augen Europas ab von ihren eignen ungeheuern Erfolgen in Polen und Circassien; auf der andern Seite hetzen sie Dänemark zum Widerstand und werden es, vermittelst des Herrn Palmerston, schliesslich fertig bringen, dass England Krieg erklärt zur Aufrechterhaltung des Vertrags von 18 2, von dem jezt aktenmässig bewiesen ist, dass Russland ihn diktirte! Die Engländer, die keinen Krieg erklärten für Polen, obgleich dazu durch die Verträge von I8 I 5 verpflichtet; die keinen Krieg erklärten für Circassien, obgleich Russland sich mit dem Kaukasus die Herrschaft über Asien sichert, sollen und - I think it probable - werden Krieg erklären für einen von Russland dictirten Vertrag, während dasselbe Russland sich officiell auf Seite der Gegner eben dieses selben Vertrags stellt! C'est incroyable! In dem englischen Volk ist nicht die geringste Sympathie für Dänemark (obgleich natürlich genug Antipathie gegen Preussen und Oestreich); es war nicht möglich one single public meeting für die Dänen zu halten; die Subscription, welche einige Aristocraten für die dänischen Verwundeten veranstalteten, proved a complete failure; aber das englische Volk hat über seine auswärtige Politik grade so viel zu sagen wie der Mann im Mond. Die in der "Times" etc. vertretene Public Opinion wird von old Pam ${ }^{4}$ selbst nach Wunsch „verschrieben".

Am 19-21 Juni war Copenhagen auf dem Punkt einer Revolution.

1 Uber Marx' Spekulation s. S. 67.

2 Marx an Engels aus Ramsgate (25.VII.'64), wo er mit den Töchtern war: „Nach about 8-ro Tagen gehen wir nach Holland, während meine Frau sich dann an die See begibt." Jenny Marx an Marx (o.D., etwa dieselbe Zeit): „... Bis dahin ich meine bis zur nächsten Woche ist dann vielleicht ein Brief aus Holland eingetroffen; oder wäre es nicht besser, wenn Du wieder schriebest - vielleicht aber nimmt Dein Onkel stillschweigend an, dass Ihr kommt und schreibt nicht weiter, da Nettchens Einladung ja auch in seinem Namen war." (Nachlass).

3 S. Brief I 8.

4 Palmerston. 
Der König hatte eine russische Depesche erhalten, worin ihm empfohlen ward sich für Personal Union der Herzogthümer mit the Danish Crown zu erklären. Der König, eine Creatur der Russen (die seinen Sohn nach Athen, seine Tochter nach England brachten und ihn selbst auf den dänischen Thron gesetzt haben) erklärte sich für den russischen Vorschlag, Minister Monrad dagegen. Erst nach zweitägigen Debatten, Resignation des Monrad, Demonstrationen in the streets of Copenhagen, zog der neugebackne king die Hörner ein, but in this way Russia has again shown the cloven foot. Uebrigens ganz abgesehn von den Specialinteressen, die Russland an der Fortführung und Verallgemeinerung des Kriegs hat, ist es sein allgemeines Interesse, dass die europ[äischen] Völker, deren gemeinsamer Feind es ist, sich einander die Köpfe blutig schlagen. Die Airs, die sich Preussen giebt - der schöne Wilhelm als William the Conqueror - sind komisch. Diese Herrlichkeit wird ein Ende mit Schrecken nehmen.

Zur Charakteristik of good Palmerston lege ich in die Morning Post (Palmerston's Privatmoniteur) einen Ausschnitt aus einer Parlamentsdebatte, einer Rede Ferrands. Es handelt sich blos um die Ernennung eines charity inspector (Regierungsaufseher über wohlthätige Institute). Aus den von mir angestrichenen Stellen wirst Du sehn, was alles dem Pam im Parlament ins Gesicht gesagt wird, ohne jedoch seine wasserdichte Haut zu netzen.

Den Garibaldi sah ich absichtlich nicht during his stay at London. In Caprera würde ich ihn besuchen, aber hier zu London he served only as a peg for every selfimportant fool to hang his carte de visite upon.

Beste Grüsse an the whole family. Meine Frau lässt Dich and family ditto grüssen.

Yours truly CH. MARX.

21. Eleanor Marx an Lion Philips, London, 25.VI.x864. I. Modena Villas. Maitland Park N. W.

My dear Uncle

It [was ver]y ${ }^{1}$ kind of you to send me your Carte de Visite. I am getting on very well with my chess. I nearly always win and when I do Papa is so cross.

What do you think of affairs in America? I think the Federals are safe, and though the Confederates drive them back every now and then I am sure [they] ${ }^{1}$ will win in the end. Were you not delighted 1 Papier beschädigt. 
about the Alabama? Of course you know all about it; at all events a Politician like you ought to. As for poor Poland I am afraid there is no help for it. But I have had enough of Politics.

I hope to see you [soo] ${ }^{1}$ in Holland and till then goodbye. Don't forget to give my love to Nettchen.

\author{
I am, dear Uncle, \\ Your affectionate friend
}

ELEANOR MARX.

They tell me this is the longest day but to me it seems as short as any other - perhaps shorter. Can you make that out[?] ${ }^{1}$

22. Karl Marx an Lion Philips, London, i7.VIII. 864.

17 August, 1864 .

I, Modena Villas, Maitland Park,

Haverstock Hill, London.

Lieber Onkel,

Deinen Brief fand ich gestern Abend hier vor, bei meiner Rückkehr vom Britischen Museum. Es war schon zu spät, um sofort zu antworten. Ich brauche Dir nicht zu sagen, wie sehr ich und alle die Meinigen über den Inhalt Deines Schreibens erschraken. ${ }^{2}$ Eins begriffen wir nicht. Warum Du nicht mit Nettchen sofort das Haus verlassen hast? Ich würde Dir rathen es noch zu thun. Als derselbe Fall in meinem Haus eintrat, entfernte ich sofort die Kinder ${ }^{3}$; und die Riesin ${ }^{4}$ kann auch ohne euch gewartet werden. Warum nutzlos Gefahr provociren? Du verzeihst mir, wenn ich so drein rede, aber meine Angst für euch ist zu gross to mince matters. Ich bedaure in der That, dass ich nicht persönlich bei euch bin, denn auf mich wirkt diese Krankheit nicht, wie ich aus Erfahrung weiss, und ich hätte euch, wenn Ihr das Haus einmal durchaus nicht verlassen wollt (but why not?) immer in dieser Krise beistehn können, denn in solchen Krisen sind zwei besser als einer und drei besser als zwei, to kill time and rough it.

Ueber unser eignes Treiben während der letzten Zeit habe ich an Nettchen geschrieben und wird sie Dir das Wenige mittheilen, was überhaupt erwähnenswerth. Es geht hier im Ganzen alles gut, und sind alle Familienglieder jetzt passabel wohl.

Hier ist jetzt politisch und gesellschaftlich Windstille. Jeder der kann, macht sich aus dem Staub, entweder ins Ausland, oder an inländische Seeplätze. Die Monotonie wird nur unterbrochen einen

1 Papier beschädigt.

2 "Aus der holländischen Reise wird nichts, weil eine Magd im Hause meines Onkels an den Pocken erkrankt ist", M. an Engels 3r. VIII. '64.

${ }^{3}$ Die drei Töchter waren während der Zeit, in der die Mutter an den Pocken litt, vom 2I. Nov. bis Weihnachten I860, bei Liebknechts untergebracht.

4 Die erkrankte Magd. 
Tag über den andern durch Berichte von schrecklichen railway accidents. Das Kapital steht hier nicht so viel unter polizeilicher Aufsicht wie auf dem Continent, und es kömmt den railway directors daher durchaus nicht drauf an, how many people are killed during an excursion season, if only the balance looks to the comfortable side. Alle Versuche, diese railway Könige verantwortlich zu machen für ihre homicidal neglect of all precautionary measures, sind bis jetzt gescheitert an dem grossen Einfluss den das railway interest im House of Commons ausübt!

Eine andre Zerstreuung bildet hier the anxiety prevailing in mercantile circles because of the rise of the rate of discount! Es ist sicher, dass wenn die jetzige rate of discount einige Wochen die jetzige Höhe hält, ein grosser crash eintreten wird unter den Myriaden von swindling joint stock companies, die dieses Jahr wie Pilze aus der Erde gewachsen sind. Ein und der andre bedeutende Bankerutt in der city deutet bereits auf das nahende Ungewitter.

Ein sehr bedeutendes naturwissenschaftliches Buch, Grove's "Correlation of physical forces" ist mir kürzlich durch die Hände gegangen. Er zeigt nach wie mechanische Bewegungskraft, Wärme, Licht, Electricität, Magnetismus und Chemical affinity, eigentlich alle nur Modificationen derselben Kraft sind, sich wechselseitig erzeugen, ersetzen, in einander übergehn u.s.w. Die widerlich metaphysischphysikalischen Hirngespinste, wie "latente Wärme" (so gut wie „unsichtbar Licht”), elektrisches „Fluid” u.d.g. pis aller, um zur rechten Zeit Worte einzustellen, wo Gedanken fehlen, beseitigt er sehr geschickt.

Ich hoffe bald gute Nachricht von euch zu hören. Ich bin so sehr absorbirt mit Gedanken an euch, dass ich heut nicht die Ruhe habe die wichtigen American news zu lesen.

Die ganze Familie grüsst herzlichst. Meinerseits empfiehl mich Jettchen, Dr, ${ }^{1}$ Fritz et Co.

Dein treuer Neffe

K. M.

23. Karl Marx an Lion Philtps, London, 29.XI.i 864. Antwoord

5 December $1864^{2}$

29 November, 1864. r, Modena Villas, Maitland Park, Haverstock Hill, London. Lieber Onkel,

1 Dr. van Anrooy.

2 Bemerkung von Lion Philips. 
Ich hoffe, dass Du Dich bei vollem Wohlsein befindest trotz des abominablen Wetters. Hier ist alles wohl. Nur hatte ich, zum grossen Schrecken der ganzen Familie, Anfang dieses Monats wieder einen sehr bösartigen Karbunkel unter der linken Brust, der 2-3 Wochen mich quälte. Sonst ging alles gut.

Die Handelscrise, die ich Dir lang vor ihrem Erscheinen ankündigte, hat nun hier ihre Spitze längst abgebrochen, obgleich ihre Wirkungen in den eigentlichen Manufacturdistricten noch immer sehr bedeutend sind. Dagegen steht nach meiner Ansicht eine politische Crise im Frühling oder Anfang Sommer bevor. Bonaparte ist wieder an dem Punkt angelangt, wo er wieder Krieg machen muss, um eine Anleihe erheben zu können. Die venetianische Geschichte wird offen gehalten (ich kenne einige der dortigen Agenten) um im Nothfall den Anknüpfungspunkt zu bilden. ${ }^{1}$ Es ist möglich dass Bonaparte wieder einen Ausweg findet, und dann hält er Frieden (denn er ist kein real Napoleon), aber es ist nicht sehr wahrscheinlich.

Die einliegende gedruckte Adresse ${ }^{2}$ ist von mir verfasst. Die Sache hängt so zusammen: Im September schickten die Pariser Arbeiter eine Deputation an die Londoner Arbeiter wegen Demonstration für Polen. Bei der Gelegenheit wurde ein internationales Arbeiter-Comité gebildet. Die Sache ist nicht ohne Wichtigkeit, weil r) in London dieselben Leute an der Spitze stehn, die dem Garibaldi den Riesenempfang bereiteten, und durch ihr monstermeeting, mit Bright, in St James's Hall, den Krieg mit den United States verbinderten. Es sind mit einem Worte die wirklichen Arbeiterchefs von London, mit I oder 2 Ausnahmen alle selbst Arbeiter. 2) Von der Pariser Seite stehn Mr. Tolain (auch selbst ouvrier) et Co. an der Spitze, d.h. dieselben Leute, die durch eine blose Intrique von Garnier-Pagès, Carnot etc. verhindert wurden, bei der letzten Wahl in Paris als Repräsentanten der dortigen Arbeiter in das Corps Législatif einzutreten, und 3) von Seiten der Italiener sind die Vertreter der 4-500 ital[ienischen] Atbeiterclubs zugetreten, die vor einigen Wochen ihren allgemeinen Congress in Neapel hielten, und den selbst die Times wichtig genug hielt ihm ein paar Dutzend Spalten in ihrem Blatt zu widmen.

Nicht in der Adresse, aber in der Einleitung der Statuten, habe ich aus Höflichkeit gegen Franzosen und Italiener, die immer grosse Phrasen brauchen, ein paar nutzlose Redensarten aufnehmen müssen. ${ }^{3}$

1 Venetien blieb bis 1866 in österreichischem Besitz. Über 'dortige Agenten', die Marx kannte, ist nichts bekannt.

${ }^{2}$ Die sogen. Inauguraladresse, die als Address and Provisional Rules of the International Working Men's Association zwischen dem 20. und 24. November als Broschüre erschienen war.

3 Über das Zustandekommen der Adresse s. auch Marx' Brief an Engels vom 4.XI.'64. 
Aus America erhielt ich vor ein paar Tagen Brief von meinem Freund Weydemeyer, Oberst des zu St. Louis (Missouri) stehenden Regiments. Er schreibt u.a. wörtlich: „Leider werden wir hier in St. Louis zurückgehalten, da bei den vielen „conservativen” Elementen hier stets eine Militärmacht nöthig ist, um einen Ausbruch und etwaige Befreiung der zahlreichen südlichen Gefangenen zu verhindern... Der ganze Feldzug in Virginien ist ein blunder, der uns Hekatomben von Leuten gekostet hat. Trotz alledem wird aber der Süden nicht lange mehr aushalten können: er hat seinen letzten Mann ins Feld geschickt und keine neue Armee mehr zu verwenden. Die gegenwärtige Invasion Missouri's hat, wie die Einfälle in Tennessee, nur den Charakter eines raids, eines Raubzugs: an eine dauernde Wiederbesetzung verlorner Districte ist nicht zu denken."

Wenn Du bedenkst, lieber Onkel, wie es sich vor $3 \frac{1}{2}$ Jahren bei der Wahl Lincoln's nur darum handelte den Sclavenhaltern keine weitern Concessionen zu machen, während jezt die Abschaffung der Sclaverei eingestandner und zum Theil schon realisirter Zweck ist, so muss man zugeben, dass niemals eine solche Riesenumwälzung so rasch vorgegangen ist. Es wird den wohlthätigsten Einfluss auf die ganze Welt haben.

Unser Stammgenosse Benjamin Disraeli hat sich in dieser Woche wieder sehr blamirt, indem er als warnender Schutzengel der high church, der church rates, und als Abwehrer gegen Kritik in religiösen Dingen sich auf einem öffentlichen Meeting breit machte. Er ist der beste Beweis wie grosses Talent ohne Ueberzeugung Lumpen schafft, wenn auch gallonirte und „right honorable" Lumpen.

Die deutschen Esel haben sich hier wieder bei der Müller-Affaire ${ }^{1}$ gehörig blamirt, Expfaff Kinkel an der Spitze.

Mit besten Grüssen der ganzen Familie an Dich, und meinerseits an Jettchen, Dr, Fritz et Co

Dein treuer Neffe

K. M.

24. Marx' Benenntinisse, ${ }^{2}$ Zaltbommel, x.IV.i865.

The Quality you like best . . . Simplicity.

In man . . . . . . . Strength.

In woman . . . . . . Weakness.

Your chief characteristic . . . Singleness of purpose.

1 Franz Müller, ein in London lebender deutscher Schneider, wurde wegen Mordes hingerichtet. Anscheinend hatte Kinkel sich für ihn eingesetzt. S. Marx' Brief an Engels vom 16. XI. '64.

2 Den Titel entnahm Rjazanov der in Laura Lafargues Besitz befindlichen Abschrift einer ähnlichen Liste. S. S. 49,64 . 
Your favourite occupation . . Glancing at Netjen.

The vice you hate most . . . Servility.

The vice you excuse most . . . Gullibility.

Your idea of happiness . . . . . To fight.

Your idea of misery . . . . . To submit.

Your aversion ....... Martin Tupper. ${ }^{1}$

Your hero . . . . . . . . . Spartacus, Keppler.

Your heroine . . . . . . . Gretchen.

The poet you like best . . . . Aeschylus, Shakespeare, Göthe.

The prose writer you like best . . Diderot.

Your favourite flower . . . . Daphne.

Your favourite dish . . . . . fish.

Your maxime: Nihil humani a me alienum puto.

Your motto: De omnibus dubitandum.

Zalt-Bommel, I April. I865.

KARL MARX.

25. Karl Marx an Nannette Philips, Margate, i8.III.1866. I 8 March, 1866. 5 Lansell's Place Margate ${ }^{2}$

My dear child,

From the address you will see that I have been banished, by my medical adviser, to this seaside place, which, at this time of the year, is quite solitary. Margate lives only upon the Londoners, who regularly inundate it at the bathing season. During the other months it vegetates only. For my own part right glad I am to have got rid of all company, even that of my books. I have taken a private lodging which fronts the sea. In an inn or Hotel one might have been exposed to the danger of falling in with a stray traveller, or being pestered by local politics, vestry interests, and neighbourly gossip. As it is, "I care for nobody and nobody cares for me." But the air is wonderfully pure and reinvigorating, and you have here at the same time sea air and mountain air. I have become myself a sort of walking stick, running up and down the whole day, and keeping my mind in that state of nothingness which Buddhaism considers the climax of human bliss. Of course, you have not forgotten the pretty little $\operatorname{dict}(\mathrm{i})$ on: "When the devil was

1 M. Tupper (1810-1889), in den soer und 6oer Jahren der populärste Dichter Englands; heute ist er vergessen. In der englischen Literaturgeschichte wird er als „talentlos, rührend naiv, poesieblind, kritik- und gedankenlos" charakterisiert.

2 Marx wat nach schwerer Krankheit vom 14. März ab etwa vier Wochen in Margate zur Erholung. 
sick, the devil a monk would be; when the devil was well, the devil a monk was he." 1

Withdrawing a little from the seaside, and roaming over the adjacent agricultural districts, you are painfully reminded of "civilisation", because from all sides you are startled by large boards, with governmental proclamations on them, headed: Cattle Disease. The ruling English oligarchs were never suspected to care one farthing for "der Menschheit ganzes Weh", but as to cows and oxen, they feel deeply. At the opening of Parliament, the horned cattle gentlemen of both houses, commoners and lords, made a wild rush at government. All their talk sounded like a herd of cows' lowing, translated into English. And they were not like honest king Wiswamitra, "der kämpfte und büsste für die Kuh Sabalah". ${ }^{2}$ On the contrary. They seized the opportunity to "battre monnaie" out of the cows' ailings at the expence of the people. By the by, the East sends us always nice things - Religion, Etiquette, and the Plague in all forms.

I am very glad to hear of Warratjes' ${ }^{3}$ winding up adventure. Verily, verily, I tell thee, my sweet little cousin, I always felt deep sympathy for the man, and always hoped that one day or other he should fix his melting heart in the right direction, and not persevere performing the nasty part in the childrens' tale: "The Beast and the Beauty". I'm sure he will make a good husband. Is his inamorata a "Bommelerin" or an importation?

A few days before leaving London, I made the acquaintance of $\mathrm{Mr}$. Orsini, a very fine fellow, the brother of the Orsini who was sent to the grave for sending Bonaparte to Italy. ${ }^{4}$ He has now left England for the U. States, in commercial matters, but during the few days of our acquaintance, he did me good service. Although an intimate friend of Mazzinis', he is far from sharing the antiquated antisocialist and theocratical views of Mazzini. Now, during my forced and prolonged absence from the Council of the International Association, Mazzini had been busy in stirring a sort of revolt against my leadership. "Leadership" is never a pleasant thing, nor a thing I ambition. I have always before my mind your father's saying in regard to Thorbeck 5 that "der Eselstreiber den Eseln immer verhasst ist". But having once fairly embarked in an enterprise which I consider of import, I certainly, "anxious" man as I am, do not like to give way. Mazzini, a most decided

\footnotetext{
1 Aus dem Mittellateinischen stammendes Sprichwort, das sich ähnlich auch im Deutschen und Französischen findet.

2 Episode aus dem Ramâyana; von Heine im „Buch der Lieder" behandelt.

8 Wohl identisch mit Waradje, s. S. 80 Anm.

4 Felice Orsini wurde wegen eines Attentats auf Napoleon III. 1858 hingerichtet.

5. J. R. Thorbecke, Führer der holländischen Liberalen seit den yoer Jahren.
} 
hater of freethinking and socialism, watched the progress of our society with great jealousy. His first attempt of making a tool of it and fastening upon it a programme and declaration of principles of his hatching, I had buffled. His influence, before that time very great with the London working class, had sunk to zero. He waxed wroth, when he saw that we had founded the English Reform Ligue ${ }^{1}$ and a weekly paper, the "Commonwealtb", to which the most advanced men of London contribute, and of which I shall send you a copy after my return to London. His anger increased, when the editor of the "Rive Gauche" 2 (the journal of the jeune France, directed by Rogeard, author of the "propos de Labienus", Longuet etc.) joined us, and when he became aware of the spread of our society on the Continent. He improved my absence, to intrigue with some English workingmen, raise their jealousies against "German" influence, and even sent his bully, a certain Major Wolf (a German by birth) to the Council there to lodge his complaints and more or less directly to denounce me. He wanted to be acknowledged as ,the leader (I suppose par la grace de dieu) of the continental democratical movement". In so doing, he acted so far quite sincerely, as he utterly abhors my principles which, in his eyes, embody the most damnable "materialism". This whole scene was enacted behind my back, and after they had made sure that my malady would not allow me to be present. ${ }^{3}$ The English wavered, but, although still very weak, I rushed to the following séance, Mr. Orsini accompanying me. On my interpellation, he declared them that Mazzini had lost his influence even in Italy and was, from his antecedents and prejudices, quite disabled from understanding the new movement. ${ }^{4}$ All the Foreign secretaries declared for me, and, if you, our Dutch secretary ${ }^{5}$, had been present, I hope you would have

1 Die neue Reform Ligue, r865 gegtündet, stand unter der Leitung des Generalrates der Internationale. The Commonwealth erschien $1865 / 66$ in London.

2 La Rive Gauche, seit 1865 in Paris, vorher in Brüssel herausgegeben als Journal internationale de la jeune république. Rogeard war Verfasser des berühmten Pamphlets Les propos de Labienus, das in den letzten Jahren des IIe Empire in rascher Folge viele Auflagen erlebte.

3 Marx schilderte die Angelegenheit ausführlich im Brief an Engels vom 24.III.'66.

4 Nach den minutes des Generalrates erklärte Orsini in der Sitzung vom 13. März, - nachdem Wolff in der vorhergehenden Sitzung mitgeteilt hatte, es gebe „in Italien keine Sozialisten im französischen Sinne”, - „that there were socialists in Italy and that Mazzini held a reactionary attitude towards Science. Charles Cattaneo and Ferrari were Socialists." In der Sitzung am 20. März bedauerte Jung, dass das Protokoll jener Sitzung nicht verlesen werden könne; denn „citizen Orsini.... was anxious that what he had said regarding Mazzini should not be misconstrued as he had the greatest respect for Mazzini."

5 Obwohl Nannette Philips die Mitgliedskarte Nr. I der holländischen Sektion der Internationale besass, war sie nicht Dutch Secretary, sondern Marx' Korrespondentin, die ihm, was sehr wohl möglich ist, gelegentlich über politische Angelegenheiten berichtete. 
also cast your vote for your humble servant and admirer. As it was, I carried a complete victory over this redoubtable adversary. I think that Mazzini has now had enough of me and will make bonne mine à mauvais jeu. - I hope to receive a few lines from you. Don't forget that I am quite an insulated hermite.

Your most sincere friend BLOCH. ${ }^{1}$

26. August Philips an Karl Marx, Amsterdam, 26.I.i872. Lieber Karl,

Amsterdam 26 Januar 72.

Hierbei die Papiere des H. Lachatre zurück.

Ich finde den Contracts-Vorschlag so schlecht dass er eigentlich gar nicht annehmbar ist. Nicht nur wird Dir gar kein Vortheil gesichert, sondern $\mathrm{Du}$ sollst noch sogar die Chance laufen die fr. $2000 \mathrm{zu}$ verlieren. Einem Schriftsteller gegenüber ist das lächerlich. An Deiner Stelle würde ich es also unbedenklich ausschlagen.

Uebrigens bin ich persönlich nicht geneigt, auch wenn die Speculation eine bessere wäre als sie mir scheint, mich an dem Vorschuss von fr. $2000 \mathrm{zu}$ betheiligen. Hauptsächlich weil ich nicht eine Propaganda für die Internationale fördern will; dann aber auch weil ich in dieser Auslage für Dich kein Vortheil sehe. Wenn es Noth thut, bin ich bereit Dir, dem Freund und Verwandten, auch mit Geld zu helfen; doch für Deine politischen oder revolutionären Zwecke thue ich das nicht.

Du wirst diese Erklärung wenigstens ehrlich finden.

Solltest $\mathrm{Du}$ mit Lachatre zu irgend einem Contract kommen, so rathe ich bei zu fügen: que la présente convention n'empêchera pas Mr. K. M. de publier en France ou ailleurs des traductions de son ouvrage sur-nommé en toute autre langue que la langue francaise. ${ }^{2}$

\section{Grüsse Deine Familie.}

Dein AUG. PHILIPS.

Als Corresponding Secretary für Holland wurde vielmehr Jacques van Rijen auf Vorschlag von Jung und Dupont in der Sitzung des Generalrates vom 16. Oktober I 866 gewählt. Am I8. Dezember '66 wurde sein Bericht verlesen, dass er die Address und Rules ins Holländische übersetzt habe und ihre Veröffentlichung in Holland vorbereite. Marx hat wiederholt über holländische Angelegenheiten im Generalrat berichtet, jedoch erst nach dieser Zeit, so dass seine Informationen von diesem Sekretär stammen dürften. S. minutes 26.X.'69, 12.IV.'70, 26.IV.'70, 11.VI.'72. Dem Generalrat gehörte ein weibliches Mitglied an, das aber war Mrs. Law. Marx an Kugelmann 12.XII.'68.

1 Vermutlich ein Scherz; möglicherweise korrespondierte Marx unter diesem Namen, um in Margate incognito zu bleiben.

2 Anfang Februar 1872 wurde der Verlagsvertrag mit Lachâtre über die französische Ausgabe des 'Kapital' abgeschlossen. Engels an Liebknecht 1 5.2.'72. Es erschien, übers. von J. Roy und stark revidiert von Marx, von 1872 bis 1875 in Lieferungen. Es ist nicht bekannt, ob Aug. Philips' Rat beim Abschluss des Vertrages befolgt wurde. 